\title{
An Empirical Assessment of the Effects of Trade in Innovative Tasks on Innovation Output
}

\author{
Saleh S. Tabrizy* \\ Department of Economics, University of Wisconsin-Milwaukee \\ 3210 N. Maryland Ave., Bolton Hall, No. 881, Milwaukee, WI, USA 53211 \\ Email: sahabeh2@uwm.edu
}

JEL Classification: F14, O32, C26, L60

\footnotetext{
* I am grateful to Rebecca Neumann for her supervision. I am also grateful to an anonymous referee, Jenny Minier (Co-Editor), Scott Drewianka, Antonio Galvao, Itziar Lazkano, and Ivan Deseatnicov for their helpful comments. I would like to thank Bruegel institute, and especially Carlo Altomonte, for providing the data set and further support. I remain responsible for any shortcomings and errors.
} 


\begin{abstract}
Multinational firms are increasingly sending their innovative tasks abroad. This paper examines whether off-shoring research and development, design, and engineering activities provides any gains in terms of firm-level innovation output. The effects of trade in innovative tasks on the probability of firms being innovative and the share of innovative product sales in total turnover are examined using an instrumental variable approach. The data in use come from a recent survey, which provides cross-section observations for more than 14,750 firms in 7 European countries. The results suggest that those firms that off-shore their innovative activities are $60 \%$ more likely to successfully innovate. Also, off-shoring innovative activities increases the share of innovative product sales in total turnover up to $35 \%$. Furthermore, firms in this sample appear to gain from trade in innovative tasks when such trade is in product innovation, but not when such trade is in process innovation.
\end{abstract}




\section{Introduction}

Recent developments in task trade have raised new questions in applied international economics. Firms' incentives to distribute different tasks across the globe and the gains that are realized from global task distribution are of importance not only for Multinational Corporations (MNCs), but also for policy makers. The relative size of trade in tasks and the fact that intra-firm trade in services has recently become more important encourage us to revisit some fairly old questions in international economics with regard to the distribution of resources and the gains from openness.

Multinational production and intra-firm trade in services remain very interesting when we focus on trade in innovative tasks. This specific task trade refers to the performance of research and development $(\mathrm{R} \& \mathrm{D})$ activities and other innovative tasks (e.g. design and engineering activities) in foreign countries through foreign direct investment (FDI) or contracts and arms length agreements. Two stylized facts motivate the importance of trade in innovative tasks. First, innovation activities carried out by MNCs account for a relatively large portion of innovation input in advanced economies. In 2010, for example, the R\&D performed by American multinational parent companies, which exceeds 212.5 billion dollars, was more than $75 \%$ of the entire R\&D performed by businesses in the United States (National Science Board 2014). Second, multinational production has been an important driving force behind the internationalization of innovative activities. In 2010, the majority-owned foreign affiliates of American MNCs performed 39.5 billion dollars of R\&D abroad (National Science Board 2014).

This task distribution is not unique to American MNCs. Within the countries in the Organization for Economic Co-operation and Development (OECD), it is estimated that more than $16 \%$ of the industrial R\&D in 2004 was conducted by foreign affiliates (Dunning and Lundan 2009). More specifically, as discussed by Moncada-Paterno-Castello, Voigt, and Vivarelli (2011), European MNCs play an important role in this task distribution. In 2010, for 
example, the R\&D performed in the United States by American affiliates of European firms (from Switzerland, the United Kingdom, Germany and France) reached 26 billion dollars, which was close to two-thirds of the entire R\&D done by the majority-owned affiliates of foreign MNCs in the United States (National Science Board 2014).

Given the size and growing importance of such off-shore activities, in this study I specifically examine how trade in innovative tasks impacts the overall amount of innovation that firms conduct. Using survey data, I measure this overall innovation in two ways: 1.) by the propensity to innovate as given by a firm's formal disclosure of innovation, which captures the extensive margin of innovation, and 2.) by the relative size of innovation output given by the innovative product sales in total turnover, which captures the intensive margin of innovation. Trade in innovative tasks is measured by off-shoring $R \& D$, design and engineering activities.

In this context, simple regression models are likely to suffer from reverse causality. One can identify at least two channels for this. On the one hand, innovative firms are likely to be among the firms that have developed relatively high innovation capabilities within the firm, and may depend less on external entities for their innovation efforts. For instance, firms with innovative products are likely to be in-house $R \& D$-performers and may have no reason to out-source/off-shore their innovative tasks to other firms, R\&D centers, or universities. ${ }^{1}$ The first channel for reverse causality is, therefore, the following: firms with relatively better innovation output are likely to have access to superior in-house innovation input and depend less on off-shored innovation. On the other hand, firms with superior productivity are more likely to engage in off-shore activities (e.g. Antràs and Helpman 2004). Under a Schumpeterian frame-work, however, this superior productivity may well be the result of the firms' innovative efforts. This sets the stage for another reverse causality channel: those firms that off-shore their innovative tasks are, in fact, likely to be the most innovative firms to begin with. Therefore, under the first channel, greater innovation output is expected to reduce the 
likelihood of trade in innovative tasks, whereas under the second channel innovative firms are likely to be among the firms that partake in trade in innovative tasks.

To address this reverse causality, I make use of a recent European firm-level survey and employ different instrumental variable (IV) estimation techniques. The survey in use provides cross-section observations on different characteristics of a rather large group of firms, thus accommodating the IV estimations.

From the full sample of surveyed firms, which includes domestic firms and MNCs, I am able to identify those MNCs that partake in trade in innovative tasks. Using this information, I first estimate the effects of trade in innovative tasks on the extensive margin of innovation, measured by whether or not a firm has disclosed its innovation. I then estimate the effects of trade in innovative tasks on the intensive margin of firm-level innovation, measured by the share of innovative product sales in total turnover of the firms. Studying the intensive margin as well as the extensive margin is an important step taken in this paper, which offers new insights with regard to the impact of trade in innovative tasks on innovation output.

Controlling for a wide range of observables and employing the relevant IV methods, the estimation results suggest that off-shoring innovative tasks is beneficial on both margins: it increases the propensity to innovate, and it increases the share of innovative product sales in total turnover. The results also suggest that simple baseline regressions may underestimate the effect of trade in innovative tasks on innovation output. Based on the IV estimations, those firms that off-shore their $\mathrm{R} \& \mathrm{D}$, design and engineering activities are $60 \%$ more likely to successfully innovate as measured by disclosed innovation, and the average share of innovative product sales in their turnover is $35 \%$ greater than other firms that do not off-shore those innovative tasks.

This paper is part of an ongoing and relatively recent set of empirical investigations on the determinants of firm-level innovation. ${ }^{2}$ A number of studies have examined how different firm and industry characteristics such as firm/business-unit size (e.g. Cohen and Klepper 1996), 
competition (e.g. Aghion et al. 2005), exporting activities (e.g. Lileeva and Trefler 2010), and financial constraints (e.g. Hall 2002) affect innovation input, output, and productivity. Beyond these canonical predictors, the impact of trade in tasks on innovation input and output is among the recent empirical questions that have been raised in the innovation literature. Several studies (e.g. Criscuolo, Haskel, and Slaughter 2010; Lin and Lin 2010; Dachs et al. 2013; Hufbauer, Moran, and Oldenski 2013) have examined the impacts of off-shoring production on innovation. Regardless of the type of tasks that are performed off-shore, these studies explore the impacts of trade in tasks on firms' innovative performance. There are also a number of studies that are focused on trade in specific types of tasks. Some of these studies have looked at the indirect impacts of non-innovative task distribution on innovation output (e.g. Görg and Hanley 2008), and some have examined the direct links between off-shoring innovative tasks and innovation output (e.g. Nieto and Rodriguez 2011). Using a new and novel European manufacturing dataset, this paper contributes to the latter by studying the existence and the magnitude of the effect of trade in innovative tasks on the extensive as well as the intensive margins of innovation.

Among those who study trade in innovative tasks, Kotabe et al. (2007) study the impact of international knowledge content on innovative performance of 53 American pharmaceutical firms using the data on their patents in the United States. Depending on its level, they find that international knowledge content affects the innovation output positively but with diminishing returns. Compared to their study, this paper examines a sample that represents the manufacturing sector in general and is capable of evaluating the effect of transferring international knowledge on disclosed innovation among European MNCs. Ceci and Masciarelli (2010) also study how trade in knowledge-intensive tasks (e.g. R\&D, design and software development) affects firms' performance. Using a large sample of Italian firms, they find that off-shoring those tasks has a positive impact on the return on equity and also the return on sales. They argue that the coherence between the off-shored knowledge-intensive 
activities and the downstream activities is crucial for the firms to gain from this task trade. In contrast to the performance measures used in their study, this paper focuses on innovation output and captures the impact of off-shoring knowledge-intensive tasks on the share of innovative product sales in total turnover.

Nieto and Rodriguez (2011) examine the impact of trade in innovative tasks on the propensity to innovate as measured by product versus process innovation using a large sample of Spanish firms. They find that trade in R\&D tasks positively affects innovative performance of the firms, but the impacts are greater for product innovation. Although the type of data and the identification strategy in this paper are different, the estimation results for the types of innovative activities that are affected by these task trades can be compared to the empirical findings reported by Nieto and Rodriguez (2011). The data set in use here comes from a more representative European sample. Compared to the way that innovative firms are identified in Nieto and Rodriguez (2011), I make use of a more restrictive criterion, as given by disclosed innovation, to study the impacts on the extensive margin. The information on firms' product and/or process innovation are then used to study whether trade in innovative tasks has different impacts on different types of innovation output. Beyond the impacts on the extensive margin of innovation, this paper also studies whether off-shoring innovative tasks contributes to the share of innovative product sales in total turnover, and provides an estimate of the magnitude of this effect.

The data are discussed more fully in Section 2, while the empirical analyses are described in Section 3. Section 4 provides further discussions. Section 5 concludes.

\section{Data}

Firm-level observations used in this study come from the European Firms in a Global Economy (EFIGE) survey. ${ }^{3}$ This is a new and novel survey, which represents manufacturing 
activities across different countries in Europe. There are 14,759 firms in this sample from 7 European countries and 11 industrial sectors. Roughly speaking, France, Germany, Italy and Spain each make up a bit less than $20 \%$ share of the sample. the United Kingdom has $15 \%$ share, and Austria and Hungry each have close to 3\% share. For any given firm, a randomized industry identifier is given. The main economic activity of a firm, classified based on Pavitt's (1984) taxonomy, is also reported. ${ }^{4}$

Barba Navaretti et al. (2011, pp. 57-60) report detailed comparisons between the sector and the size distribution of the stratified sample in the EFIGE survey and the reference populations across different countries, showing that the sample is fairly representative. Yet, firms with fewer than 10 employees are excluded from the survey. These firms are typically small businesses that are actively involved in the domestic market rather than foreign markets. Hence, internationally active firms are over-represented in this survey. To correct for this, I make use of a weighting scheme proposed by Barba Navaretti et al. (2011) and used by Altomonte, Aquilante, and Ottaviano (2012). ${ }^{5}$

The data were collected from January to May 2010, with questions covering the years from 2007 to 2009 . However, information was mostly collected as a cross-section for the last available budget year (2008) along with some information with regard to averages for the period 2007-9. The respondents are typically of high rank in the organization: CEO, General Director, President, CFO, or HR Manager

To assess the effects from trade in innovative tasks on innovation output, I first need a set of measures for innovation output. In the survey, firm managers have answered some general questions with regard to innovation in the output and production process. For instance, one can identify if a firm has disclosed any innovations by applying for a patent, registering an industrial design, registering a trade mark or claiming copyright during 2007-9. I use these responses to measure the extensive margin of firm-level innovation. About $24 \%$ of the firms (3,572 firms) in the sample can be identified as innovative by this measure. Beyond this fairly 
restrictive measure of the propensity to innovate, four other binary measures are used for 1.) product innovators, 2.) those firms that introduce a new-to-market innovation, 3.) process innovators and 4.) those firms that their product/process innovations lead to organizational innovation. ${ }^{6}$ The firms in the sample have also been surveyed about the average percentage of turnover from innovative product sales during 2007-9, which can be used to measure the intensive margin of innovation at the firm level. The mean of the the average percentage of turnover from innovative product sales during 2007-9 is about $10 \%$ (with standard deviation of $19 \%$ ) in the full sample, and about $17.5 \%$ (with standard deviation of $22 \%$ ) in the sub-sample of innovative firms, as measured by disclosed innovation.

The EFIGE survey also provides detailed information that can be used to identify those MNCs that off-shore their innovative activities. In practice, trade in innovative tasks can happen through two different channels: out-sourcing and off-shoring. Out-sourcing is applicable when firms distribute (part of) their innovative tasks across un-affiliated parties that might be located in their own country or in a foreign country, whereas off-shoring refers to a case in which the second party is located in a foreign country no matter if it is an affiliated party or not. What is relevant in this study is the off-shoring activities. ${ }^{7}$

To find those MNCs that off-shore their innovative tasks, I first need to identify the MNCs. I identify firm $i$ as an MNC if it runs at least part of its production activity in another country via FDI and/or contracts and arms length agreements. There are 1,208 MNCs in the full sample, of which 618 firms (4\% of the sample) run at least part of their production off-shore via FDI, 487 firms (3\% of the sample) do this through contracts and arms length agreements, and 103 firms ( $0.6 \%$ of the sample) use FDI as well as contracts and arms length agreements to perform their off-shore production activities. Those MNCs are then asked a number of follow-up questions. Among those questions, they are asked about the type of production that is off-shored via FDI or contracts and arms length agreements. I identify MNC $i$ as one which partakes in trade in innovative tasks once it is actively involved in off-shoring its $R \& D$, 
engineering and design services via FDI and/or contracts and arms length agreements. ${ }^{8}$ As expected, these criteria are very restrictive and, thus, there are 166 firms $(1.12 \%$ of the full sample and $13.74 \%$ of the MNCs) that fall into this category. There are 112 firms that off-shore their innovative tasks via FDI, 43 firms that do this via contract and arms length agreements, and 11 firms that do both of them.

Two important patterns emerge for those 166 firms that partake in trade in innovative tasks. First, the majority of these firms $(112+11=123$ firms) have integrated (part of) their off-shore innovative efforts via FDI. Second, the majority of these firms (158 firms) are also involved in other types of off-shore productive activities. For instance, 131 firms with off-shore innovative activities also off-shore the production of their finished products, and 103 firms with off-shore innovative activities also off-shore the production of their semi-finished products or components.

By comparison with other firms, MNCs are relatively large. Large firms (i.e. firms with annual turnover greater than 15 million euros in 2008) make up $15 \%$ of firms in the full sample, $41 \%$ of the MNCs, and $62 \%$ of the MNCs that off-shore their innovative tasks. Examining the share of large firms that partake in different types of task trades, Table 1 shows that the share of large firms is greater among those that off-shore their innovative tasks compared to those that off-shore their non-innovative tasks (i.e. production of finished products, semi-finished products/components or other types of productive activities).

Compared to the full sample, Spanish firms are less involved in multinational activities whereas German firms are relatively more involved in those types of activities. More specifically, Spanish and German firms each represent $19 \%$ of the firms in the stratified sample. Yet, only $9 \%$ of the MNCs are from Spain, and 25\% of the MNCs are from Germany. With two exceptions, the distribution of MNCs with off-shore innovative activities is fairly comparable to the distribution of MNCs across countries. Italian MNCs are less involved in trade in innovative tasks whereas British MNCs are relatively more involved in trade in 
innovative tasks. More specifically, Italian MNCs and British MNCs each represent about $18 \%$ of the MNCs in the sample. Yet, only $9 \%$ of the MNCs with off-shore innovative efforts are originally from Italy, and $28 \%$ of the MNCs with off-shore innovative efforts are from the United Kingdom. It is also important to note that more than $75 \%$ of the firms that partake in trade in innovative tasks are from the United Kingdom (28\%), Germany (25\%) and France (23\%). As illustrated by the examples above, the relative importance of these three countries is not merely due to the full sample stratification. They are, in fact, more involved in multinational activities and specifically in trade in innovative tasks. ${ }^{9}$

Firms that perform their innovative activities off-shore are relatively more successful in terms of their innovation output. In this sub-sample, the share of firms with disclosed innovation is relatively greater, and they enjoy greater share of innovative product sales in total turnover. This superior innovation output is evident not only in a comparison with all the firms in the sample, but also in a comparison with the sub-sample of MNCs. As reported in Table 2, among those that partake in trade in innovative tasks, $63 \%$ of the firms have disclosed their innovation during 2007-9. This share is relatively lower among the sub-sample of MNCs $(52 \%)$, and it is considerably lower within the full sample (24\%). The mean of the share of innovative product sales in total turnover among those that partake in trade in innovative tasks is about $20 \%$ (with a standard deviation of $26 \%$ ). This share is relatively lower among the sub-sample of MNCs (15\% with standard deviation of 21\%), and it is also lower within the full sample (10\% with standard deviation of 19\%). Those firms that off-shore their innovative activities also employ greater number of employees for R\&D purposes. This suggests that these firms enjoy superior innovation output, and they also allocate greater share of their labor input to innovative activities.

As described above, the survey in use provides detailed information by which I can identify the firms with off-shore innovative activities. It also provides useful measures for the extensive and the intensive margin of innovation output. Lastly, it provides a wide array of 
observables that can be used as control variables in regressions predicting the innovation status of the firms or the share of innovative product sales in total turnover.

\section{Empirical analyses}

The underlying empirical question in this study is the following: does trade in innovative tasks by European MNCs through off-shoring R\&D, design and engineering activities result in greater propensity/intensity of firm-level innovation output?

To address this question, I follow a two-stage approach. Controlling for a wide range of covariates, I first use two instrumental variables to predict whether a firm off-shores its innovative tasks. Given the results of the first stage and controlling for the same vector of covariates, I then estimate the effect of off-shoring those tasks on the probability that a firm successfully innovates (i.e. the effect on the extensive margin of innovation output) and the importance of innovative product sales in total turnover (i.e. the effect on the intensive margin of innovation output). I first employ a Bivariate Probit model to estimate the effect on the extensive margin of innovation, and I follow an approach proposed by Heckman (1978) to estimate the effect on the intensive margin. The results suggest that off-shoring innovative tasks contributes to the probability of successful innovation as well as the intensity of innovative product sales. With the control covariates kept at their means, those that offshore their innovative tasks are estimated to be $60 \%$ more likely to innovate, and the share of innovative product sales in their total turnover is estimated to be $35 \%$ higher compared to those that do not. I use linear IV methods and follow a Control Function approach to test the robustness of the estimated effect on the extensive margin of innovation. I also use a sub-sample from which British firms are excluded to make sure that the results are not driven by the firms in the United Kingdom. The key findings remain robust.

Trade in innovative tasks and the extensive margin of firm-level innovation 
In order to study the effect of off-shoring $R \& D$, design and engineering activities on the probability of firms being innovative, I employ a measure of disclosed innovation as the primary dependent variable. This is a binary variable that indicates whether a firm has disclosed an innovation during $2007-9$ as measured by patents, industrial design, trade mark or copy right (henceforth, DINN for disclosed innovation). I estimate a baseline Probit regression model first. Then, introducing two instruments, I re-estimate the relationship under a Bivariate Probit model to address the possibility for reverse causality. To test the robustness of the results, I use linear IV models and follow a Control Function approach. I also exclude the outward orientation controls, which may be endogenous, and perform the estimations for a smaller vector of control covariates. Lastly, I employ a set of alternative measures for the extensive margin to estimate the effect of trade in innovative tasks on different types of innovations.

\section{Baseline regression}

In the baseline regression, I make use of the Maximum Likelihood Probit technique to estimate the parameters of the following regression function and predict the probability of being an innovative firm, as measured by disclosed innovation:

$$
E\left[\operatorname{DINN}_{i} \mid \operatorname{Ornd}_{i}, X_{i}\right]=\alpha_{0}+\alpha_{1} \operatorname{Ornd}_{i}+X_{i}^{\prime} \alpha_{2}+E\left[u_{D I N N} \mid \operatorname{Ornd}_{i}, X_{i}\right]
$$

The disclosed innovation measure, $D I N N_{i}$, is set equal to one when firm $i$ has disclosed an innovation via patents, industrial design, trade mark or copy right, and zero otherwise. The measure for off-shoring R\&D, Ornd $i$, is set equal to one when firm $i$ off-shores its innovative tasks (i.e. R\&D, design and engineering activities) through either FDI or contracts and arms length agreements, and zero otherwise. The key hypothesis is that $\alpha_{1}$ is positive. The vector of control covariates $\left(X_{i}\right)$ captures the intensity of $\mathrm{R} \& \mathrm{D}$ activities, foreign ownership status, the intensity of exporting activities, size, age, and sector- and country-specific characteristics.

Controlling for size, age, sector- and country-specific characteristics are conventional in 
these types of equations. To control for the variations in the intensity of innovation inputs, I use the share of employees involved in R\&D activities during 2008. This labor input variable can measure the importance of innovation for any given firm within the sample. ${ }^{10}$

Furthermore, the share of exporting activities in total turnover during 2008 and foreign ownership status are added to control for the outward orientation of the firms. Being exposed to competition in foreign markets and being owned by foreign owners may affect the innovative activities of the firm. However, these are used only to satisfy the Conditional Independence Assumption, and one cannot draw any causality inference from the sign and the magnitude of the estimated correlations. To make sure that the empirical results of this paper are not driven by the possible endogeneities of these two control covariates, the estimations are also conducted using a smaller control vector that includes only the share of employees involved in R\&D, size, age, sector- and country-specific characteristics.

An ordinal measure is used to control for firm size. The total turnover of each firm during 2008 is categorized as: less than 1 million euros, between 1 and 2, 2 and 10, 10 and 15, 15 and 50,50 and 250, or more than 250 million euros. About $35 \%$ of the firms have reported that their total turnover has either been less than 1 million euros (12\%) or between 1 and 2 million euros $(22 \%)$. More than $43 \%$ of the firms belong to the third category in which total turnover is between 2 and 10 million euros. The rest have reported that their turnover falls in one of the other remaining categories. An ordinal measure of age is used to control for market experience and customer base, according to the following range: younger than 6 years, between 6 and 20 years, or older than 20 years. Close to $58 \%$ of the firms are older than 20 years, 35\% of them are between 6 and 20, and about $7 \%$ are under 6 years old. I also control for the intensity of innovation input. About $60 \%$ of the firms in the sample have at least one labor force that is involved in R\&D. Among these R\&D performers, the mean of the share of employees involved in R\&D activities during 2008 is close to 13\%. I add further controls for variations in exporting activities and foreign ownership status. More than 53\% of the firms 
have reported some exporting activities. Among these exporters, the mean of the export share in total turnover during 2008 is slightly more than $32 \%$. The foreign ownership control is set equal to one for those firms that belong to a foreign group ( $8.81 \%$ of the sample) and zero otherwise. Lastly, I control for the unobserved sector- and country-specific characteristics using sector- and country-dummies.

With the control covariates kept at their means, the Maximum Likelihood Probit estimation of Equation 1 suggests that those firms that off-shore their innovative tasks are $19.61 \%$ more likely to succesfully innovate as measured by disclosed innovation $(D I N N)$. The estimated parameters are reported in Table 3 (column I). As for the control covariates, the share of employees involved in $\mathrm{R} \& \mathrm{D}$, the share of exports in total turnover, and the ordinal size measures are positively correlated with the binary response on the left-hand side (LHS), whereas belonging to a foreign group is negatively correlated to the variations on the LHS. ${ }^{11}$

This baseline result is likely to be biased. As discussed in the introduction, there are two channels for reverse causality. On the one hand, those firms that have disclosed an innovation are more likely to have access to proper in-house innovation inputs, and they may depend less upon off-shore innovative efforts. On the other hand, those that have off-shored their innovative efforts are likely to be the most innovative firms to begin with. The baseline estimate of the parameter of interest is expected to be biased downward when the first channel dominates the second one, and it is expected to be biased upward when the opposite is true. Either way, the conditional expectation of the error term in Equation $1\left(E\left[u_{D I N N} \mid \operatorname{Ornd}_{i}, X_{i}\right]\right)$ is likely to be non-zero. To test if the variable of interest $\left(O r n d_{i}\right)$ is in practice endogenous, I perform a test proposed by Smith and Blundell (1986). Under the null hypothesis, the control covariates $\left(X_{i}\right)$ and the dummy variable for trade in innovative tasks $\left(O r n d_{i}\right)$ are exogenous to the LHS variations. The estimated P-value of the test is equal to zero, which enables me to reject the exogeneity of the variable of interest $\left(\operatorname{Ornd}_{i}\right)$.

Bivariate Probit model 
To address the potential for reverse causality, verified by the finding of the test above, I re-estimate the effect of trade in innovative tasks on the extensive margin of innovation under a Bivariate Probit model in which, other than the baseline model, two instruments are employed in a separate equation to predict the probability of a firm partaking in innovative task trade. The probability of off-shoring innovative tasks and its effect on the probability of a firm being innovative are jointly estimated as follows: ${ }^{12}$

$$
\begin{gathered}
\operatorname{DINN}_{i}=\gamma_{10}+\gamma_{11} \text { Ornd }_{i}+X_{i}^{\prime} \gamma_{12}+u_{i} \\
\text { Ornd }_{i}=\gamma_{20}+I V_{i}^{\prime} \gamma_{21}+X_{i}^{\prime} \gamma_{22}+e_{i} \\
(u, e) \sim N(0, \Sigma)
\end{gathered}
$$

I employ two instruments for the IV vector in Equation 3: 1.) a dummy for family management, and 2.) a dummy for derivative usage. Based on survey responses to questions on family ownership and management practice, Altomonte, Aquilante, and Ottaviano (2012) define a family management dummy variable (henceforth, Fam) that is set equal to one for those firms in which the share of managers related to the controlling family is higher than the national average. Based on this measure, approximately $25 \%$ of the firms in the sample are managed by their controlling family. This instrument is likely to be correlated with the variations of trade in innovative tasks, and it is orthogonal to the error terms in the baseline models.

There are also a number of questions in this survey that deal with general financial issues at the firm. Among these, firms have been asked whether they have used any derivative products for external financing needs, treasury management, or foreign exchange risk protection. I use the responses to this question as my second instrument. Among other purposes, financial derivatives are widely used to manage exchange rate risks. Thus, a derivative usage dummy variable (henceforth, Dev) may predict the probability of trade in 
innovative tasks done by MNCs. However, this instrument may not be perfectly exogenous to the innovative activities. Those MNCs that partake in trade in innovative tasks are not the only firms that actively hedge against exchange rate risks. Among others, exporters are also likely to hedge against these risks and, empirically, there is a correlation between exporting and innovative activities. ${ }^{13}$ Controlling for the export share in total turnover should minimize this issue and improve the usefulness of the derivative usage dummy as an appropriate instrument. I perform the key IV estimations employing both of the instruments in an IV vector, as well as using each of the instruments separately.

The Bivariate Probit model estimations, reported in Table 3 (columns $I I-1$ and $I I-2$ ), show that those firms that off-shore their innovative activities are more likely to successfully innovate as measured by disclosed innovation. These results suggest that, keeping the control covariates at their means, those firms that off-shore their R\&D, design and engineering activities are $61.53 \%$ more likely to innovate. The instruments in use are highly effective. There is an inverse and statistically significant relationship between the binary variations in family management and trade in innovative tasks, suggesting that family managed firms are less likely to off-shore their innovative tasks. There is also a positive and statistically significant relationship between the binary variations in derivative usage and trade in innovative tasks, suggesting that those firms that use financial derivatives are more likely to off-shore their innovative tasks. The overall F-statistic of the Bivariate Probit estimation reaches 79.88 when both of the instruments are used, illustrating the goodness of fit.

Incorporating the exogenous variations of the instruments into the model, the estimated effect of trade in innovative tasks on the extensive margin of innovation is greater than what the baseline model suggests. The marginal effect of trade in innovative tasks on the extensive margin of innovation is estimated to be equal to $19.61 \%$ in the baseline regression. The Bivariate Probit model suggests that this marginal effect is estimated to be equal to $61.53 \% .{ }^{14}$ The difference between the baseline results and Bivariate Probit results implies that the first 
channel of reverse causality dominates the second channel.

As expected, there is a positive correlation between the innovation input control (the share of employees involved in R\&D) and the binary innovation output on the LHS. As for outward orientation controls, foreign ownership is negatively correlated with innovation status, and the intensity of exporting activities is positively correlated with innovation status. The negative correlation between foreign ownership status and innovation output may imply that foreign-owned firms in this sample are mainly acquired for non-innovative tasks (e.g. routine production, distribution, and local marketing). ${ }^{15}$ A positive correlation between the intensity of exporting activities and innovation output has been reported in previous literature. ${ }^{16}$ Also, the magnitude of the positive correlation between firm size and innovation status increases as firms grow in size. However, compared to newly established businesses, age does not appear to be correlated with innovation status. ${ }^{17}$

The above results remain the same when I use the instrumental variables separately in two Bivariate Probit model estimations. The sign and statistical significance of the estimated parameters associated with the instruments remain the same, and the estimated marginal effect is close to what is reported above. ${ }^{18}$

\section{Robustness}

In order to test the robustness of the findings for the extensive margin, I first employ a Two Stage Least Squares (2SLS) method under a Linear Probability model and make use of the exogenous variations of the instruments. Then, I turn to the Control Function approach to re-estimate the relationship controlling for predicted residuals. Lastly, I use a smaller vector of controls where outward orientation measures, which may be endogenous to the LHS variations, are excluded. The results are robust regardless of the estimation method and the vector of controls.

In terms of sign and statistical significance of the estimated parameter of interest, the result of the linear IV estimation, reported in Table 3 (column III), is in line with the findings of the 
Bivariate Probit estimations. Those that off-shore their innovative tasks are more likely to successfully innovate and have their innovation disclosed. Since the underlying probability model is linear, however, the magnitude of the effect is overstated. Also, the F-statistic of the first stage is fairly low. These typical shortcomings notwithstanding, I am able to examine the exogeneity of the instruments under the linear IV estimation. To test the orthogonality condition, I make use of a Sargan (1958) over-identification test. The null hypothesis of this test implies that the instruments in use are exogenous to the LHS variations. When I employ both of the instruments, the underlying orthogonality hypothesis of the over-identification test is clearly not rejected $(\mathrm{P}$-value $=0.76)$.

Following the Control Function approach, I address the reverse causality problem by controlling for generalized residuals of a Probit model where the endogenous treatment is used on the LHS. The result of the Control Function approach estimation is not going to suffer from potential shortcomings of Local Average Treatment Effect.

In the first step (Equation 4 below), the probability of being an MNC that off-shores its innovative tasks is estimated under a Probit model assumption using vector $Z$ which is made up of the control covariates ( $R \& D$ input intensity, exporting activities, foreign ownership status, size, age, sector- and country-specific characteristics) and the instruments (family managed and derivative usage dummies):

$$
E\left[\operatorname{Ornd}_{i} \mid X_{i}\right]=Z_{i}^{\prime} \eta
$$

By estimating the non-zero conditional expectation of the error terms in the baseline model $\left(E\left[u_{D I N N} \mid \operatorname{Ornd}_{i}, X_{i}\right]\right)$ via the estimation done in the first step, one can obtain the generalized residuals $\left(\widehat{g r} r_{i}\right)$ to control for the endogeneity:

$$
\widehat{g r}_{i}=\left(\operatorname{Ornd}_{i}\right)\left(\phi\left(Z_{i}^{\prime} \widehat{\eta}\right) / \Phi\left(Z_{i}^{\prime} \widehat{\eta}\right)\right)-\left(1-\operatorname{Ornd}_{i}\right)\left(\phi\left(-Z_{i}^{\prime} \widehat{\eta}\right) / \Phi\left(-Z_{i}^{\prime} \widehat{\eta}\right)\right)
$$


Predicting the generalized residuals in Equation 5, I then estimate the probability of being a firm that successfully innovates (Equation 6 below) using the same control covariates, the generalized residuals and the treatment, which is no longer endogenous. ${ }^{19}$

$$
E\left[\operatorname{DINN}_{i} \mid \operatorname{Ornd}_{i}, X_{i}, \widehat{g r}_{i}\right]=\zeta_{0}+\zeta_{1} \operatorname{Ornd}_{i}+X_{i}^{\prime} \zeta_{2}+\zeta_{3} \widehat{g r}_{i}
$$

The result reported in Table 3 (column $I V$ ) suggests that the estimated coefficient of interest is relatively greater when using the Control Function approach. Thus, the estimated marginal impact of off-shoring innovative tasks on the probability of being an innovative firm that discloses its innovation is also greater (those firms that partake in trade in innovative tasks are $77.90 \%$ more likely to be innovative as measured by disclosed innovation). The sign and statistical significance of the estimated parameter of interest are in line with the Bivariate Probit model estimation, which is also true for the estimated coefficients of control covariates. $^{20}$

Since the outward orientation measures that are used as controls may be endogenous, I drop the binary measure for foreign ownership as well as the share of exports in total turnover to make sure that the results are not sensitive. A greater number of observations can be used once the control for exporting activities is excluded from the vector of control covariates, bringing the total observations to 14,607 firms. The estimation results remain robust when these controls are excluded. ${ }^{21}$

\section{Alternative measures for innovation status}

The LHS variable in the analyses above (DINN) is not the only measure of innovation available in this survey. The survey contains the type of innovations carried out by any given innovative firm. Thus, I substitute a measure for (new-to-market) product innovation as well as process and organizational innovation for DINN on the LHS and repeat the same estimation procedure for each one separately. These are all binary measures that are equal to one once a firm reports (new-to-market) product innovation, process innovation, or organizational 
innovation, respectively.

By contrast to the results where DINN is used on the LHS, the evidence of the impacts of off-shoring innovative tasks on specific types of innovation output is inconclusive. Table 4 shows that although the baseline results indicate that trade in innovative tasks is positively correlated with the four different types of innovation output, the Two Stage Least Squares estimations suggest that trade in these tasks increases the probability of a firm being innovative only when the extensive margin is measured via product innovation. Due to its linear set-up, the magnitude of the estimated parameter is larger than expected, and the F-statistic of the first stage is fairly low. Also, the Two Stage Least Squares results cannot be confirmed by the Bivariate Probit model and Control Function approach estimations, where the estimated parameter of interest is insignificant. ${ }^{22}$ Nevertheless, since the over-identification test performed after this estimation indicates that the orthogonality between the instruments and the error terms cannot be rejected (P-value=0.40), the estimated positive correlation may still be informative.

The linear IV results, reported in Table 4, suggest that the impact of trade in innovative tasks on innovation output is stronger when it comes to product innovation versus process innovation. Nieto and Rodriguez (2011) report similar findings for a panel of 12,000 Spanish firms. They examine the effect of a lagged R\&D off-shoring treatment on the current innovation output. Their response variable is measured by product and process innovation. Employing Probit and Bivariate Probit estimations, they find that trade in innovative tasks has greater impact on product innovation compared to process innovation.

Summarizing the above results, the positive effect of trade in innovative tasks on the extensive margin of innovation can be confirmed by various estimation techniques when this margin is measured by disclosed innovation. The same is also evident when the extensive margin is measured by product innovation. Beyond these two measures, however, I find no conclusive evidence of a positive or adverse impact on the extensive margin of innovation 
from off-shoring innovative activities, when it comes to new-to-market product innovation, process innovation, or organizational innovation.

Trade in innovative tasks and the intensive margin of firm-level innovation

In this section, I examine how trade in innovative tasks contributes to the intensity of innovation output. The response variable is the average share of innovative product sales in total turnover during 2007-9 (henceforth, IPS for innovative product sales), which measures the intensive margin of firm-level innovation output. ${ }^{23}$ These types of measures have been frequently used after Crèpon, Duguet, and Mairessec (1998) found that, other than patents, innovative product sales measures are positively correlated with firms' productivity. Roberts (1999) also suggests that these measures are positively correlated with firms' profitability.

Using a baseline regression model, I first estimate the effect of off-shoring innovative tasks on the intensity of innovation output. After I report the results of linear IV regressions, I re-estimate the relationship following an approach proposed by Heckman (1978) to address the possibility for reverse causality. To ensure that the underlying orthogonality condition behind the identification strategy is satisfied, I follow an indirect over-identification test. Lastly, I perform the same estimations using a smaller vector of control covariates, from which the outward orientation controls are excluded.

\section{Baseline regression}

In the baseline regression, I make use of Ordinary Least Squares to estimate the parameters of the following regression function and predict the intensity of innovation output, as measured by the share of innovative product sales in total turnover:

$$
E\left[\operatorname{IPS}_{i} \mid \text { Ornd }_{i}, X_{i}\right]=\beta_{0}+\beta_{1} \text { Ornd }_{i}+X_{i}^{\prime} \beta_{2}+E\left[u_{I P S} \mid \text { Ornd }_{i}, X_{i}\right]
$$

The LHS variable $\left(I P S_{i}\right)$ measures the average share of innovative product sales in total turnover of firm $i$ during 2007-9. I make use of the same treatment $\left(O r n d_{i}\right)$, which is equal to 
one when firm $i$ off-shores its innovative tasks through either FDI or contracts and arms length agreements, and zero otherwise. I also employ the same vector of control covariates $\left(X_{i}\right)$, which includes measures of the intensity of R\&D activities, foreign ownership status, the intensity of exporting activities, size, age, sector- and country-specific characteristics. The nature of the LHS variations is, therefore, the only difference between the baseline models in Equation 1 and 7. The response variable is binary and measures the extensive margin of innovation in Equation 1, whereas it is continuous and measures the intensive margin of innovation in Equation 7.

Conditional upon the controls in use, off-shoring innovative tasks is estimated to increase the share of innovative product sales in total turnover by $6.01 \%$ as reported in Table 5 (column I). As expected, the share of labor input involved in R\&D and the share of exports in total turnover are both positively correlated with the share of innovative product sales in total turnover. Also, in general the greater the size of the firm, the greater the correlation between size and the share of innovative product sales. These correlations are in line with the previous findings where the response variable is a measure of innovation status rather than innovation intensity. However, the estimated coefficients for age measures are now significant and negative. Compared to the youngest firms, the magnitude of the negative correlation between age and innovation intensity increases as age increases, which suggests that the share of innovative product sales in total turnover is greater among the youngest firms. ${ }^{24}$ Also, the negative correlation between foreign ownership status and innovation output is no longer significant.

Considering similar reverse causality channels to that for DINN, those firms for which innovative product sales is of relative importance are more likely to have access to in-house innovation input and depend less upon external innovative efforts such as off-shore innovation. Also, those firms that partake in off-shoring innovative efforts are likely to be the most productive and innovative firms and thus enjoy a larger share of innovative product sales in 
total turnover. The estimated effect of off-shoring innovative tasks on the intensive margin of innovation is biased downward when the first channel dominates the second one, and it is biased upward when the opposite is true. Regardless of the expected direction of bias, the conditional expectation of the error term in Equation $7\left(E\left[u_{I P S} \mid \operatorname{Ornd}_{i}, X_{i}\right]\right)$ is likely to be non-zero. I perform an augmented Durbin-Wu-Hausman test (Davidson and MacKinnon 1993) to verify the possibility of reverse causality. For the purpose of this test, a Linear Probability model is first employed in which the probability of off-shoring innovative tasks is predicted using the control covariates and the instruments. Then, the predicted residuals of this first stage are added to the baseline regression. It turns out that the predicted residuals are of explanatory power $(\mathrm{P}$-value $=0.07)$, indicating that the baseline regression suffers from endogeneity.

\section{Heckman (1978) approach}

To address the possibility of reverse causality, verified by the finding of the test above, I re-estimate the baseline regression under Two Stage Least Squares where both of the instruments are employed. The results are reported in Table 5 (column II). This estimation yields a fairly high standard deviation for the parameter of interest. Thus, the estimated impact is not statistically significant. Consequently, I am not able to directly test the orthogonality of the instruments in this section. The linear first stage of this estimation seems to be the underlying problem behind the insignificant result. To avoid this, I make use of the non-linear fits of the endogenous treatment $(\widehat{O r n} d)$ as new instruments for another 2SLS estimation, which yields a more efficient estimate for the parameter of interest (Angrist and Pischke 2009, pp. 188-192).

Following Heckman (1978), the instruments in use (Fam and Dev) are employed in a Pre-2SLS step where the model below is estimated via a Maximum Likelihood Probit technique: 


$$
E\left[\operatorname{Ornd}_{i} \mid I V_{i}, X_{i}\right]=\delta_{0}+\delta_{1} I V_{i}+X_{i}^{\prime} \delta_{2}
$$

The predicted LHS value of the estimation conducted for Equation $8(\widehat{\text { Ornd }})$ is then used in the second step as a new IV to estimate Equation 9 via a 2SLS method:

$$
E\left[\operatorname{IPS}_{i} \mid \operatorname{Ornd}_{i}, X_{i}\right]=\alpha_{0}+\alpha_{1} \operatorname{Ornd}_{i}+X_{i}^{\prime} \alpha_{2}+E\left[u_{I P S} \mid \operatorname{Ornd}_{i}, X_{i}\right]
$$

In Equation 8, the response variable $\left(O r n d_{i}\right)$ is the endogenous treatment used in Equation 9. It is a binary measure equal to one for those MNCs that off-shore their innovative tasks via FDI or contracts and arms length agreements, and zero otherwise. The response variable in Equation $9\left(I P S_{i}\right)$ is the average share of innovative product sales in total turnover during 2007-9. The vector of control covariates $\left(X_{i}\right)$ is the same as the one used in the baseline regression (Equation 7) and controls for the variations in the share of labor input involved in R\&D activities, foreign ownership status, share of exports in total turnover, size, age, sectorand country-specific characteristics.

The Pre-2SLS results, reported in Table 5 (column III-1), suggest that family managed firms are less likely to off-shore their innovative tasks, whereas those firms that use financial derivatives are more likely to do so. The resulting estimations from the 2SLS step, reported in Table 5 (column III-2), indicate that those MNCs that carry out their R\&D, design and engineering activities in another country via FDI or contracts and arms length agreements gain $35.50 \%$ greater share of innovative product sales in total turnover. These results suggest that the magnitude of correlation between trade in innovative tasks and innovation intensity among firms in the sample is largly underestimated in the estimation of the baseline regression (at $6.01 \%)$.

As for the controls, the share of employees involved in R\&D (2008) is positively correlated with the share of innovative product sales in total turnover (2007-9). There is also 
some evidence of a positive correlation between exporting activities and the intensive margin of innovation output as well as a negative correlation between foreign ownership status and the intensive margin of innovation output. Yet, the former is not significant when both of the instruments are used. Lastly, as suggested by the negative correlations between the age measures and the response variable, younger firms appear to enjoy a greater share of innovative product sales in total turnover. ${ }^{25}$

It is important to test for the orthogonality of the instruments in use. Unfortunately, there is no direct way to test for the exclusion restriction following the Heckman (1978) method. The Pre-2SLS step and the first stage of the 2SLS step seem to provide a proper fit. The estimated coefficients for the instruments are significant and of expected sign. The F-statistic associated with the first stage of the 2SLS estimation is also high enough once the predicted LHS variable in the Pre-2SLS step $(\widehat{O r n} d)$ is used as the IV for the estimation in the 2SLS step. When both of the instruments are used in the Pre-2SLS step, for instance, the F-statistic associated with the first stage of the 2SLS estimation reaches 104.99. Although these fits are necessary, the exogeneity of the instruments must be tested too. Thus, an indirect over-identification test is conducted. First, I assume that Fam is an exogenous instrument. Since the unconditional correlation between Fam and IPS is close to zero, this seems to be a fairly reasonable assumption. ${ }^{26}$ Also, let $\widehat{O r n} d_{D e v, i}$ be the predicted values of $O r n d_{i}$ estimated via the control covariates and Dev on the RHS. Employing Fam along with $\widehat{O r n} d_{D e v, i}$ in an IV vector used in a 2SLS estimation of Equation 9, I conduct an over-identification test and take its result as indirect evidence of the required orthogonality. Interestingly enough, the null hypothesis of the over-identification test cannot be rejected in this case $(\mathrm{P}$-value $=0.41)$, which suggests that these two instruments remain orthogonal to the error terms in the original model. Panels III and $I V$ in Table 5 provide a comparison between the result of the estimation in which $\widehat{\text { Orn }} d_{\text {Fam,Dev, },}$ is used as an instrument and the estimation in which Fam and $\widehat{O r n} d_{D e v, i}$ are used as instruments. These two estimations yield similar coefficients for the treatment of interest. ${ }^{27}$ 
As a robustness check, I re-estimate the model above using a smaller control vector because of the possible endogeneity of outward orientation controls (i.e. foreign ownership and exporting activities). Once a smaller control vector is employed, the baseline results remain intact. The Heckman method estimation of the parameter of interest turns out to be of expected sign, but at relatively low significance level (P-value $<0.15) .{ }^{28}$

In summary, for the intensive margin, I address the potential reverse causality in the baseline estimation of Equation 7 by employing the non-linear fits of the endogenous treatment of interest in the Pre-2SLS step as instruments in a 2SLS estimation following an approach proposed by Heckman (1978). Controlling for a wide range of covariates, the results of the estimations above suggest that trade in innovative tasks positively affects the intensive margin of firm-level innovation, and the magnitude of this effect is greater than what the baseline correlation would imply.

\section{Further robustness analyses}

In the regression analyses above, I employ sector- and country-specific intercepts to control for unobserved characteristics across different sectors and countries. In order to make sure that neither a specific sector nor a specific country drives the key results, I re-estimate the baseline effect of trade in innovative tasks on innovation output for each sector (controlling for the usual covariates as well as country-specific intercepts), each country (controlling for the usual covariates as well as sector-specific intercepts) and sector-country pairs (controlling for the usual covariates). ${ }^{29}$ The results suggest that no specific sector or sector-country pair is of vital importance, although some sectors (notably, sector number 4, 5, 11, 1 and 10) appear to be more important than others. ${ }^{30}$ The firms from the United Kingdom, however, form an important sub-sample when I re-estimate the baseline regression for each country separately. ${ }^{31}$ Excluding British firms (2,067 observations) from the full sample, I re-estimate the baseline regressions as well as the IV regressions across the remaining countries. Table 6 shows that the key findings of the empirical analyses are robust to this exclusion. 
As for the propensity to innovate, the Bivariate Probit model estimation (Table 6, columns $I I-1$ and $I I-2)$ suggests that those firms that off-shore their innovative activities are $66 \%$ (compared to $61 \%$ in Table 3, columns $I I-1$ and $I I-2$ ) more likely to succesfully innovate as measured by disclosed innovation. The estimated coefficients for the instruments are significant and of expected signs, and the F-statistic of the Bivariate Probit model estimation reaches 53.77. The robustness of this positive effect is verified by a linear IV estimation (Table 6, column III) and a control function estimation (Table 6, column $I V$ ). ${ }^{32}$ These results suggest that the baseline estimation of the parameter of interest (Table 6, column $I$ ) is biased downward.

As for the intensity of innovation output, the IV estimation using Heckman (1978) method (Table 6, columns VI-1 and VI-2) suggest that those firms that off-shore their innovative tasks enjoy 29\% (compared to $35 \%$ in Table 5, columns $I I I-1$ and $I I I-2)$ greater share of innovative product sales in total turnover when both instruments are used in the IV vector. This implies that the baseline regression (Table 6, column $V$ ) is biased downward. As expected, the linear IV estimation yields a large standard error for the estimated coefficient of interest, and it is not possible for me to directly test for the orthogonality of the instruments. To test for the orthogonality condition indirectly, I run two separate over-identification tests. I first use the derivative usage dummy along with the usual controls to predict the treatment of interest $\left(\widehat{O r n} d_{D e v, i}\right)$ in the Pre-2SLS step. Then, for the 2SLS step, I employ the non-linear prediction of the treatment $\left(\widehat{O r n} d_{D e v, i}\right)$ along with the family management dummy in a vector of instruments. The estimated parameter of interest is in line with the estimation where both of the instruments are directly used in the Pre-2SLS step. However, the P-value of the over-identification test is such that the orthogonality hypothesis can be rejected $(\mathrm{P}$-value $=0.07)$. I repeat the same exercise and employ another non-linear prediction of the treatment $\left(\widehat{\text { Orn }} d_{F a m, i}\right)$, which is predicted via the family management dummy and the usual controls, along with the derivative usage dummy in an IV vector for the 2SLS step. The 
estimated parameter of interest is again in line with the estimation where both of the instruments are directly used in the Pre-2SLS step. This time, however, the resulting P-value of the overidentification test is such that the orthogonality hypothesis cannot be rejected (P-value $=0.54)$. Thus, the indirect tests of orthogonality do not provide conclusive results. Nevertheless, in terms of the parameter of interest and the estimated coefficients of the control covariates, the IV estimation using Heckman (1978) method yields comparable estimates when I use the full sample and when I use the sub-sample from which British firms are excluded.

\section{Discussion}

The empirical analyses of this paper indicate that trade in innovative tasks contributes to the extensive and the intensive margins of innovation output. Multiple tests verify the robustness of the above findings to different regression function specifications, estimation techniques, and samples. Nevertheless, there are three primary caveats when interpreting the key findings. ${ }^{33}$ Suppose firm $i$ is identified as a firm that partakes in trade in innovative tasks based on the criteria introduced in Section 2. Controlling for a number of covariates, the key findings of this paper suggest that it is more likely that firm $i$ has disclosed an innovation, and it is also expected that it has enjoyed a greater share of innovative product sales in total turnover. The first caveat is that I am not able to observe whether the disclosed innovation by firm $i$ results directly from its off-shore innovative efforts. I am also not able to observe the share of the revenue generated by those innovative products that are specifically developed off-shore by firm $i$. Second, even when no innovative activity is conducted abroad, firm $i$ may still report some off-shore innovative activities in order to minimize its tax burden. When this transfer

pricing is successful, it may contribute to firm $i$ 's profit, which in turn provides the firm with more financial resources to innovate at home. Since I am unable to observe the exact 
destination at which those R\&D, design and engineering activities are conducted, I can neither confirm nor reject this transfer pricing hypothesis. Third, it is likely that the extensive and the intensive margins of innovation output are measured with some errors. For instance, the disclosed innovation measure may not be an ideal indicator of innovation output due to strategic patenting behavior. ${ }^{34}$ Therefore, the estimated parameters of interest may overstate the real effect. To make up for these shortcomings, more detailed surveys are required. In particular, more information about the direct links between trade in innovative tasks and innovation output are needed as well as information about the countries that host such off-shoring activities. Also, more details about firms' innovation output can improve the precision of the estimations conducted in future research.

This paper also calls for further research in three related areas. First, it is important to examine the causality relation under a (quasi-)experimental set-up. Despite the fact that the IV analyses in this paper address the potential for reverse causality, my estimations do not capture the magnitude of the effect under a well-designed randomized trial.

Second, it is important to examine the push and pull factors that influence firms' selection into this specific type of task trade under a general equilibrium set-up. Some important patterns emerge from the data, which may help explain this selection. As described in Section 2, the share of large firms (i.e. firms with annual turnover greater than 15 million euros in 2008 ) is greater among those firms that off-shore their innovative tasks. This is evident not only when I compare them to the rest of the sample, but also when I compare them with those MNCs that off-shore other types of productive activities. This implies that trade in innovative tasks may be profitable at higher levels of productivity compared to the productivity cut-off required for trade in non-innovative tasks. The majority of the firms with off-shore innovative activities are also involved in other types of off-shore productive activities, which is another indicator of their superior productivity. Furthermore, the comparisons provided in Section 2 suggest that most of the firms that off-shore their innovative activities tend to integrate their 
off-shore innovative efforts via FDI. By off-shoring their innovative tasks to affiliated parties, firms are more likely to control the intellectual property risk associated with their off-shore R\&D. ${ }^{35}$ This internalization decision suggests that these firms, which are likely to be very productive, are able to finance the (fixed) cost associated with integration, and in return they may protect their innovative efforts abroad. ${ }^{36}$

Third, it is important to examine the geographic agglomeration of innovative activities on a global scale in order to explore the underlying forces that motivate trade in innovative tasks. Employing a geographically weighted technology spillover measure, Bloom, Schankerman, and Van Reenen (2013) suggest that geographic proximity to where successful innovation happens (as measured by the location of patents) may contribute to the firms' productivity and market value. Lychagin et al. (2010) provide more detailed evidence supporting the hypothesis that geographic proximity matters for productivity, and they suggest that geographic spillover effects are larger when one considers the location of innovative activities rather than the location of headquarter activities. Hence, the most productive firms are likely to off-shore their innovative activities to exploit the global geographic agglomeration of innovative activities.

\section{Conclusion}

This study examines the firm-level gains, measured in terms of innovation output, from off-shoring innovative tasks via foreign direct investment or contracts and arms length agreements. The detailed EFIGE survey in use enables me to address the reverse causality problem and estimate the magnitude of the gains in terms of the extensive margin of innovation (i.e. whether a firm innovates) and the intensive margin of innovation (i.e. how much a firm innovates).

Using the exogenous variations of the instrumental variables and conditional upon a wide range of observables, the key findings of this paper suggest that those firms that off-shore their 
innovative tasks are more likely to successfully innovate, and they also enjoy a greater share of innovative product sales in total turnover. More specifically, the Bivariate Probit estimations suggest that those MNCs that off-shore their innovative activities are $60 \%$ more likely to innovate, as measured by disclosed innovation. This finding is robust once I make use of linear IV methods and follow the Control Function approach. Analyzing different types of innovation, I show that product innovation is positively affected by off-shore innovation. Yet, there is no conclusive evidence of any effects on innovative activities in terms of process or organizational innovation. Furthermore, the Heckman (1978) method estimations suggest that those MNCs that off-shore their innovative activities have approximately $35 \%$ greater share of innovative product sales in total turnover.

The key findings of this paper underline the potential gains from multinational task distribution in $R \& D$, design and engineering activities. Those European MNCs that partake in these types of intra-firm trades are more likely to be innovative (as measured by disclosed innovation), and their innovations positively contribute to their total sales. This is of interest not only for those MNCs, but it is also of interest for the countries that (intend to) host innovative activities. Beyond that, and perhaps more importantly, the evidence in support of the existence and the magnitude of these gains on both margins are important for policy makers in developed countries where MNCs play a crucial role in the overall investment in innovation. Distortionary measures against these task distributions may adversely affect the innovative performance of MNCs and may also have an indirect impact on innovation in aggregate. 


\section{References}

Aghion, Philippe, Nick Bloom, Richard Blundell, Rachel Griffith, and Peter Howitt. 2005.

Competition and Innovation: an Inverted-U Relationship. The Quarterly Journal of

Economics, 120(2): 701-728.

Altomonte, Carlo, Tommaso Aquilante, and Gianmarco I. P. Ottaviano. 2012. The triggers of competitiveness: The EFIGE cross-country report. Brussels: Bruegel.

Angrist, Joshua D., and Jörn-Steffen Pischke. 2009. Mostly harmless econometrics: An empiricist's companion. Princeton: Princeton University Press.

Antràs, Pol, and Elhanan Helpman. 2004. Global Sourcing. Journal of Political Economy, 112(3): 552-580.

Barba Navaretti, Giorgio, Matteo Bugamelli, Fabiano Schivardi, Carlo Altomonte, Daniel Horgos, and Daniela Maggioni. 2011. The global operations of European firms, Brussels: Bruegel.

Bloom, Nick, Mark Schankerman, and John Van Reenen. 2013. Identifying Technology Spillovers and Product Market Rivalry. Econometrica, 81(4): 1347-1393.

Ceci, Federica, and Francesca Masciarelli. 2010. A Matter of Coherence: The Effects of Offshoring of Intangibles on Firm Performance. Industry and Innovation, 17 (4): 373-392. Cohen, Wesley M. 2010. Fifty years of empirical studies of innovative activity and performance. In Handbook of the Economics of Innovation, edited by Hall, B. H., and Rosenberg, Amesterdam and Oxford: N. Elsevier, pp. 129-213.

Cohen, Wesley M., and Steven Klepper. 1996. A Reprise of Size and R\&D. Economic Journal, 106: 925-951.

Crèpon, Bruno, Emmanuel Duguet, and Jacques Mairesse. 1998. Research, Innovation And Productivity: An Econometric Analysis At The Firm Level. Economics of Innovation and New Technology, 7 (2): 115-158.

Criscuolo, Chiara, Jonathan Haskel, and Matthew J. Slaughter. 2010. Global engagement and 
the innovation activities of firms. International Journal of Industrial Organization, 28 (2): 191-202.

Dachs, B., and Ebersberger, B. 2009. Does foreign ownership matter for the innovative activities of enterprises? International Economics and Economic Policy, 6 (1): 41-57.

Dachs, Bernhard, Bernd Ebersberger, Steffen Kinkel, and Oliver Som. 2013. The Effects of Production Offshoring on $R \& D$ and Innovation in the Home Country, Accessed November 2013. Available at http://ssrn.com/abstract $=2344627$

Davidson, Russell, and James G. MacKinnon. 1993. Estimation and inference in econometrics. New York: Oxford University Press.

Dunning, John H., and Sarianna M. Lundan. 2009. The Internationalization of Corporate R\&D: A Review of the Evidence and Some Policy Implications for Home Countries. Review of Policy Research, 26: 13-33.

Görg, Holger, and Aoife Hanley. 2008. Services outsourcing and innovation: An empirical investigation. Kiel: Institute for the World Economy.

Greene, William H. 2012. Econometric analysis. Upper Saddle River, NJ: Pearson Prentice Hall.

Hagedoorn, John, and Ning Wang. 2012. Is there complementarity or substitutability between internal and external R\&D strategies? Research Policy, 41 (6): 1072-1083.

Hall, Bronwyn H. 2002. The financing of research and development. Oxford Review of Economic Policy, 18: 35-51.

Heckman, James J. 1978. Dummy Endogenous Variables in a Simultaneous Equation System. Econometrica, 46 (4): 931-959.

Helpman, Elhanan. 2011. Understanding Global Trade. Cambridge, Mass: Belknap Press of Harvard University Press Hufbauer, Gary C., Theodore H. Moran, and Lindsay Oldenski. 2013. Outward FDI, US Exports, US Jobs, and US R\&D: Implications for US Policy. Washington, DC: Peterson 
Institute for International Economics.

Imbens, Guido, and Jeffrey Wooldridge. 2007. What is New in Econometrics? Control

Functions and Related Methods, Accessed March 2013. Available at

http://www.nber.org/minicourse3.html

Kotabe, Masaaki, Denise Dunlap-Hinkler, Ronaldo Parente, and Harsh A. Mishra. 2007.

Determinants of cross-national knowledge transfer and its effect on firm innovation. Journal of International Business Studies, 38(2): 259-282

Lileeva, Alla, and Daniel Trefler. 2010. Improved Access to Foreign Markets Raises

Plant-Level Productivity... for Some Plants. Quarterly Journal of Economics, 125(3): 1051-1099.

Lin, Hui-lin, and Eric S Lin. 2010. FDI, Trade, and Product Innovation: Theory and Evidence. Southern Economic Journal, 77 (2): 434-464.

Lychagin, Sergey, Joris Pinkse, Margaret E. Slade, and John Van Reenen. 2010. Spillovers in space: Does geography matter? NBER Working Paper No. 16188.

Moncada-Paterno-Castello, Pietro, Marco Vivarelli, and Peter Voigt. 2011. Drivers and impacts in the globalization of corporate R\&D: An introduction based on the European experience. Industrial and Corporate Change, 20 (2): 585-603.

Nagaoka, Sadao, Kazuyuki Motohashi, and Akira Goto. 2010. Patent Statistics as an Innovation Indicator. In Handbook of the Economics of Innovation edited by Hall, B. H., and Rosenberg, Amesterdam and Oxford: N. Elsevier, pp. 1083-1127.

National Science Board. 2014. Science and Engineering Indicators 2014. Arlington, VA: National Science Foundation.

Nieto, María J., and Alicia Rodriguez. 2011. Offshoring of R\&D: Looking abroad to improve innovation performance. Journal of International Business Studies, 42 (3): 345-361.

OECD: Organisation for Economic Co-operation and Development. 2009. Innovation in firms: A microeconomic perspective. Paris: OECD. 
Pavitt, Keith. 1984. Sectoral patterns of technical change: Towards a taxonomy and a theory. Research Policy, 13 (6): 343-373.

Roberts, Peter W. 1999. Product innovation, product-market competition and persistent profitability in the U.S. pharmaceutical industry. Strategic Management Journal, 20 (7): 655-670.

Sargan, John D. 1958. The Estimation of Economic Relationships using Instrumental Variables. Econometrica, 26 (3): 393-415.

Smith, Richard, and Richard Blundell. 1986. An exogeneity test for a simultaneous equation Tobit model with an application to labor supply. Econometrica, 54 (4): 679-686. 


\section{Notes}

${ }^{1}$ This prediction is based on an implicit assumption that external innovative activities are substitutes for inhouse innovative efforts. Hagedoorn and Wang (2012) suggest that the substitutability between internal and external $R \& D$ activities is evident at relatively low amounts of in-house R\&D investments.

${ }^{2}$ Cohen (2010) provides an exhaustive review of the empirical findings on the determinants of firms' innovation activities as well as industry-level innovation.

${ }^{3}$ The EFIGE survey has been conducted by Bruegel, a European think tank, along with seven other partners, and it is supported by the Directorate General Research of the European Commission.

${ }^{4}$ These two classifications are non-nested. There are some sectors for which more than one type of economic activity has been reported. See Appendix 1 for more details on the distribution of firms across countries by sector (Table A-1) and by economic activity (Table A-2). The sectors are also listed in Table A-3.

${ }^{5}$ Except for those estimations that make use of Two Stage Least Squares technique, I employ relative survey weights in the empirical analyses of this paper to ensure that the results are representative.

${ }^{6}$ Table A-4 in Appendix 1 shows the cross tabulation of the frequency of innovative firms in the sample once the alternative criteria for the probability of innovation are in use.

${ }^{7}$ See Helpman (2011, pp. 126-132) for a comprehensive discussion on off-shoring versus out-sourcing.

${ }^{8}$ See Appendix 1 for the survey questions used to identify the MNCs, and used to identify the MNCs that partake in trade in innovative tasks.

${ }^{9}$ Table A-5 in Appendix 1 depicts the distribution of firms across countries within the full sample and subsample of MNCs and the MNCs that off-shore their innovative tasks.

${ }^{10}$ The average share of R\&D investment in total turnover during 2007-9 is an alternative control for the intensity of innovation input. However, there are 2,142 missing observations for this variable compared to only 17 missing observations in the share of employees involved in R\&D activities during 2008. The estimated effect of off-shoring innovative tasks on the extensive margin of innovation remains robust when I use the alternative control. Detailed estimation results available upon request.

${ }^{11}$ The number of observations used in this baseline regression (12,671 firms) is less than the number of firms in the full sample (14,759 firms), due to missing data on the share of exports in total turnover (1,964 firms), the size measure (135 firms), and the share of employees involved in R\&D (17 firms). Some firms are missing observations in only one of the control variables above, while some are missing observations in more than one control variable.

${ }^{12}$ Greene (2012, pp. 738-752) provides a detailed discussion of such an approach.

${ }^{13}$ For instance, Dachs and Ebersberger (2009) show that, among other covariates, exporting activities are 
strongly correlated with innovative activities of firms in Austria.

${ }^{14}$ Predicting the probability of a firm being innovative (i.e. $\left.\operatorname{Pr}\left(\operatorname{DINN} N_{i}=1\right)\right)$ under Probit assumptions, this marginal effect is computed when all the control covariates are kept at their means.

${ }^{15}$ These types of results, which indicate asset-exploiting behavior of the foreign MNCs, have been documented in previous empirical studies. See Dachs and Ebersberger (2009) for a review of competing empirical findings on the impacts of foreign ownership on innovation output.

${ }^{16}$ Lileeva and Trefler (2010) is a recent example.

${ }^{17}$ In the interest of space, the estimated coefficients of the ordinal size and age measures are not reported in Table 3. More detailed estimation results available upon request.

${ }^{18}$ Detailed estimation results available upon request.

${ }^{19}$ Imbens and Wooldridge (2007) provide a detailed discussion of such an approach.

${ }^{20}$ Sector 9 is dropped due to the fact that none of the firms that come from this sector off-shore their innovative tasks (thus reducing the number of observations in the Control Function approach estimation to 12,652 firms instead of 12,671).

${ }^{21}$ Detailed estimation results available upon request.

${ }^{22}$ Detailed estimation results available upon request.

${ }^{23}$ The EFIGE survey provides me with a measure of the share of innovative product sales in total turnover. Others have used innovative product sales per employee to measure the importance of innovation output at any given firm (e.g. OECD 2009). Unfortunately, I neither observe this in the survey, nor can I compute it.

${ }^{24}$ In the interest of space, the estimated coefficients of the ordinal size and age measures are not reported in Table 5. More detailed estimation results available upon request.

${ }^{25}$ In the interest of space, the estimated coefficients of the ordinal size and age measures are not reported in Table 5. More detailed estimation results available upon request.

${ }^{26}$ The unconditional correlation between Fam and IPS is equal to -0.0091 in the full sample (14,759 firms). This unconditional correlation is equal to -0.0059 in the sub-sample in which all the control covariates are observed $(12,652$ firms $)$.

${ }^{27} \mathrm{I}$ also perform the test differently, and employ another non-linear prediction of the treatment $\left(\widehat{\text { Orn }} d_{\text {Fam }, i}\right)$, which is predicted via the family management dummy and usual controls, along with the derivative usage dummy in a vector of instruments for the 2SLS step. The estimated parameter of interest in the 2SLS step is comparable to that reported in Table 5. Also, I cannot reject the orthogonality of the instruments used in the 2SLS step once I perform an over-identification test $(\mathrm{P}$-value=0.38). Detailed estimation results available upon request.

${ }^{28}$ Detailed estimation results available upon request. 
${ }^{29}$ I am grateful to an anonymous referee for raising this point. Detailed estimation result for the sectors, countries, and sector-country pairs available upon request.

${ }^{30}$ I am unable to identify these sectors explicitly as I only have access to a randomized industry identifier in the EFIGE survey.

${ }^{31}$ As discussed in Section 2, More than $75 \%$ of the MNCs with off-shore innovative efforts are originally from the United Kingdom, Germany and France. Among these, British MNCs are the most important group. In fact, $28 \%$ of the MNCs with off-shore innovative efforts are from the United Kingdom (see Table A-5 in Appendix 1).

${ }^{32}$ Using the linear IV estimation results, I perform a Sargan (1958) over-identification test to ensure that the instruments remain exogenous when British firms are excluded from the sample. The result suggests that the null hypothesis of orthogonality cannot be rejected (P-value=0.87).

${ }^{33} \mathrm{I}$ am grateful to an anonymous referee for raising these points.

${ }^{34}$ See Nagaoka, Motohashi and Goto (2010, pp. 1105-1117) for a recent survey on the use and the shortcomings of patent data in measuring innovation output.

${ }^{35}$ Nieto and Rodriguez (2011) suggest that this type of integration, which in the management literature is known as captive off-shoring, has greater impacts on innovation output.

${ }^{36}$ This sorting pattern is close to the predictions in Antràs and Helpman (2004). When manufacturing costs are relatively lower in the foreign country, they predict that the most productive firms integrate their productive activities abroad via FDI. However, the assumption of that model does not necessarily accommodate the difference between the innovative and non-innovative tasks that are performed off-shore. 


\section{Tables:}

Table 1: Distribution of MNCs across size categories by their type of task trade

\begin{tabular}{|c|c|c|c|c|}
\hline & \multicolumn{4}{|c|}{ Number of firms who partake in trade in } \\
\hline \multirow{2}{*}{$\begin{array}{l}\text { Annual turnover in } 2008 \\
\text { (in million euros) }\end{array}$} & \multicolumn{2}{|c|}{ non-innovative tasks } & \multicolumn{2}{|c|}{ innovative tasks } \\
\hline & Number & Share $^{\mathrm{a}}$ & Number & Share ${ }^{a}$ \\
\hline$<1$ & 34 & $3 \%$ & 3 & $2 \%$ \\
\hline $1-2$ & 88 & $8 \%$ & 10 & $6 \%$ \\
\hline $2-10$ & 410 & $36 \%$ & 44 & $27 \%$ \\
\hline $10-15$ & 115 & $10 \%$ & 6 & $4 \%$ \\
\hline $15-50$ & 232 & $20 \%$ & 38 & $23 \%$ \\
\hline $50-250$ & 184 & $16 \%$ & 39 & $24 \%$ \\
\hline$>250$ & 76 & $7 \%$ & 24 & $15 \%$ \\
\hline Large $^{b}$ & & $43 \%$ & & $62 \%$ \\
\hline Total & 1,139 & & $164^{\mathrm{c}}$ & \\
\hline
\end{tabular}

Notes:

a) Shares are computed for any given size category relative to the total number of firms who take part in the similar task trade.

b) Firms with annual turnover greater than 15 million euro are identified as Large.

c) Turnover information is not available for 2 firms with off-shore innovative activities. 
Table 2: Comparison between the firms in the full sample, the MNCs, and those who offshore their innovative tasks

\begin{tabular}{|c|c|c|c|}
\hline & Full Sample & $\mathrm{MNCs}^{\mathrm{a}}$ & $\begin{array}{c}\text { Those MNCs who } \\
\text { offshore their } \\
\text { innovative tasks }{ }^{b}\end{array}$ \\
\hline Number of firms & 14,759 & 1,208 & 166 \\
\hline 1.) Percentage of firms with disclosed innovation (2007-9) & $24 \%$ & $52 \%$ & $63 \%$ \\
\hline 2.) Mean of the share of Innovative Product Sales in turnover (2007-9) & $10 \%$ & $15 \%$ & $20 \%$ \\
\hline 3.) Mean of the share of employees involved in R\&D (2008) & $8 \%$ & $10 \%$ & $14 \%$ \\
\hline 4.) Percentage of firms who belong to a foreign firm & $9 \%$ & $22 \%$ & $38 \%$ \\
\hline 5.) Mean of the share of exports in total turnover (2008) & $20 \%$ & $35 \%$ & $40 \%$ \\
\hline 6.) Percentage of family-managed firms & $25 \%$ & $10 \%$ & $4 \%$ \\
\hline 7.) Percentage of firms who use financial derivatives & $4 \%$ & $11 \%$ & $13 \%$ \\
\hline
\end{tabular}

Notes:

a) Firms who have reported some FDI or foreign contracts and arms length agreements are identified as multinational (MNC).

b) Firms who have reported some FDI or foreign contracts and arms length agreements for R\&D, engineering and design services are identified as those who have off-shored their innovative tasks. 
ริ

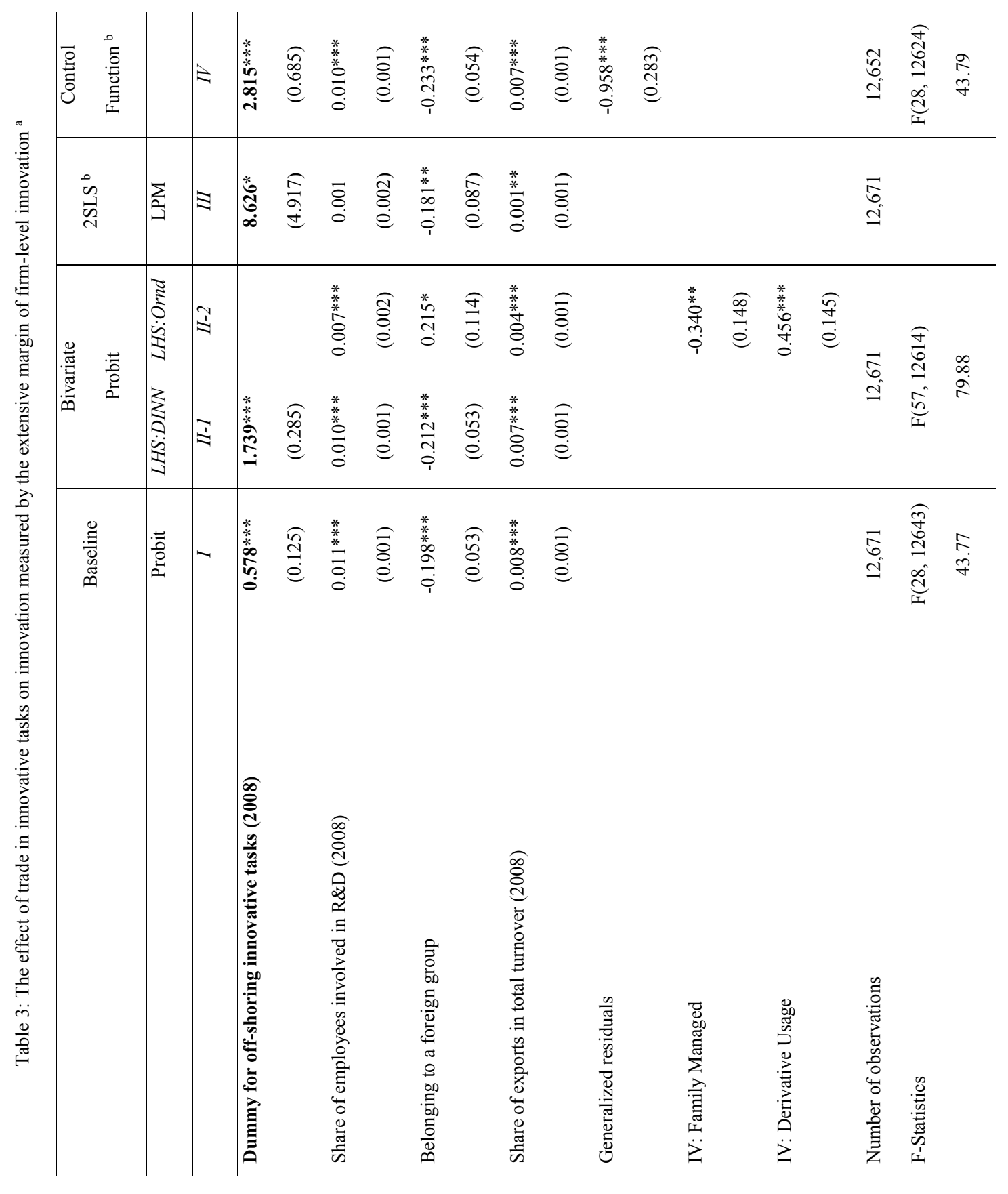




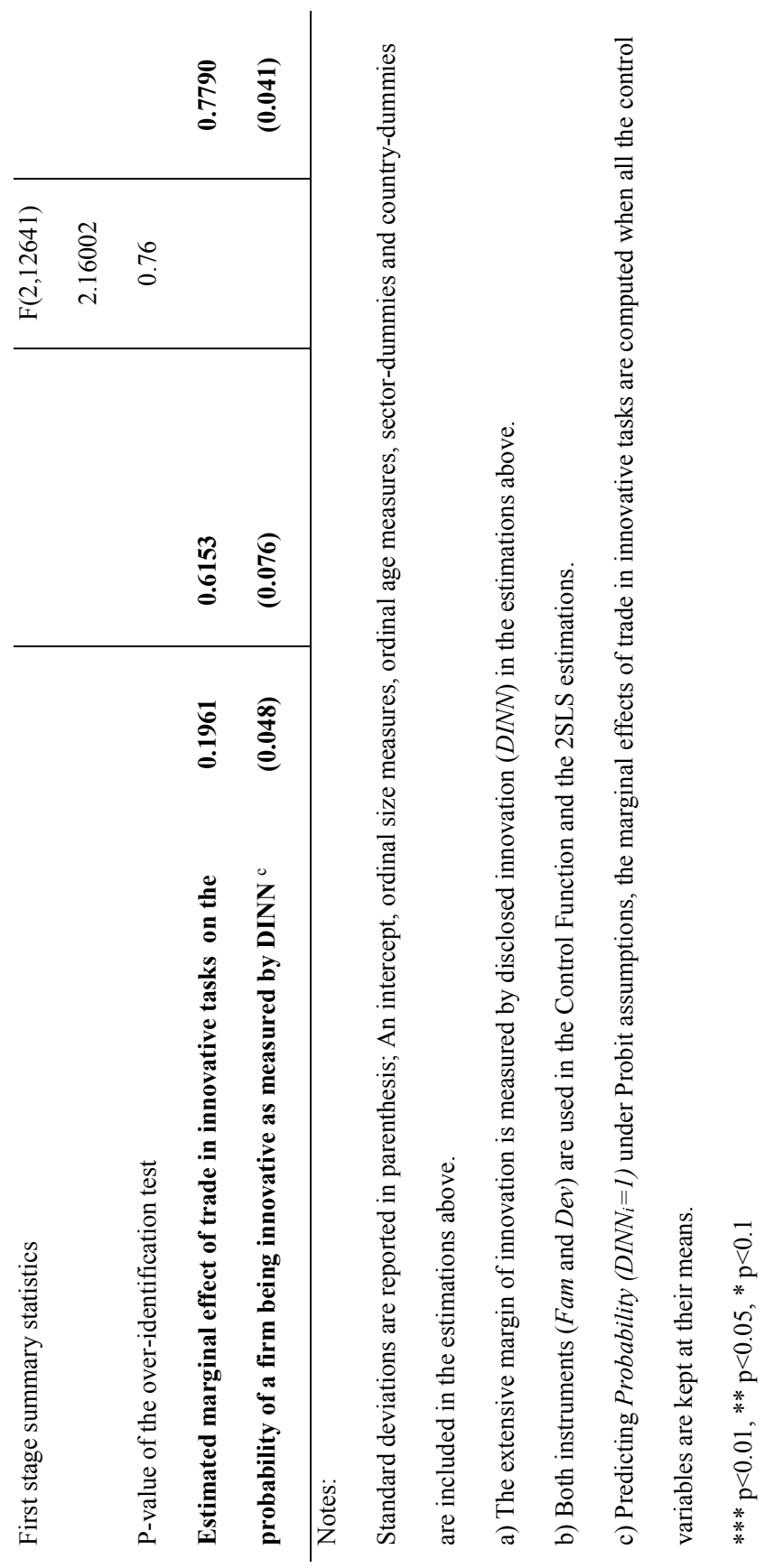




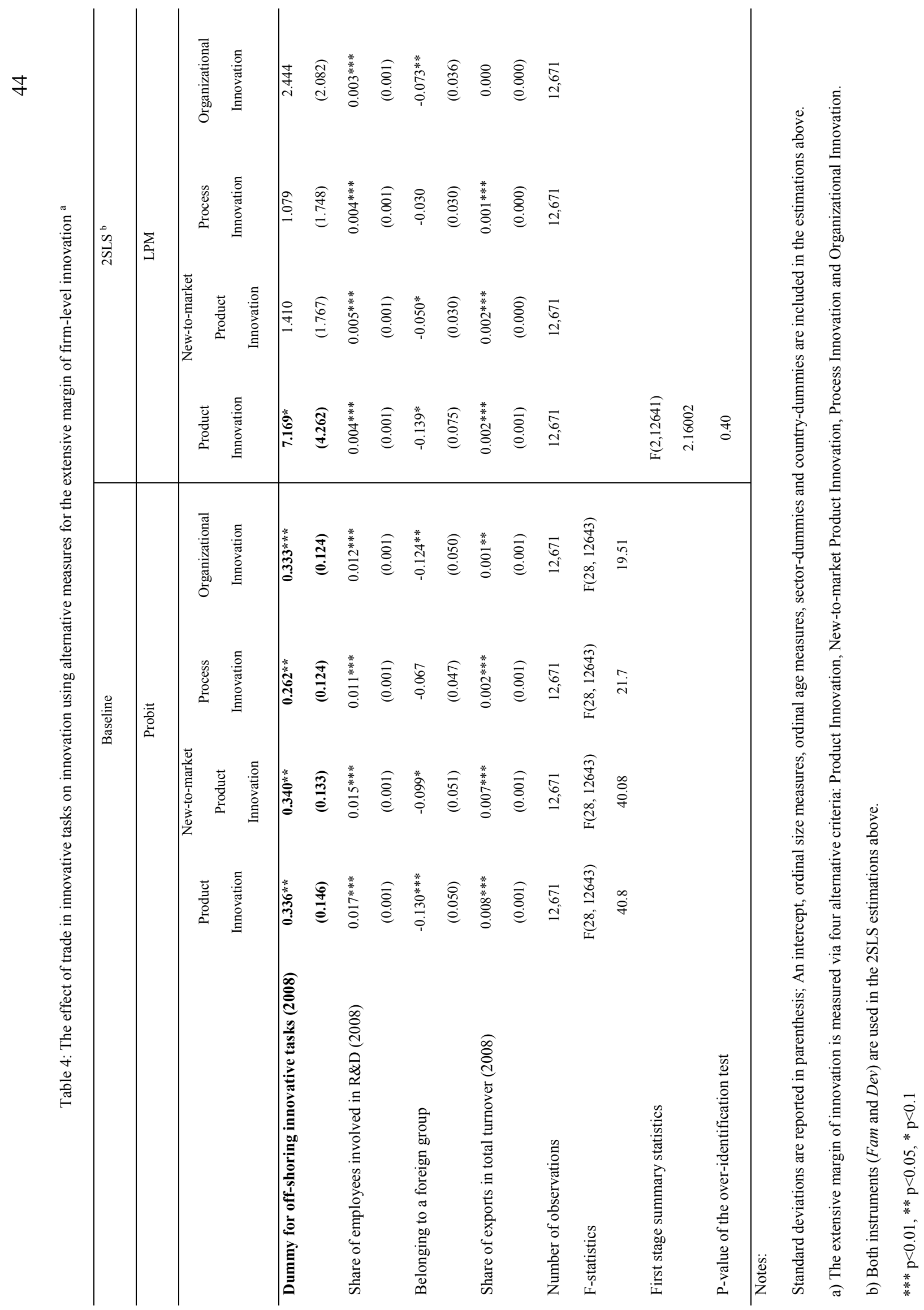




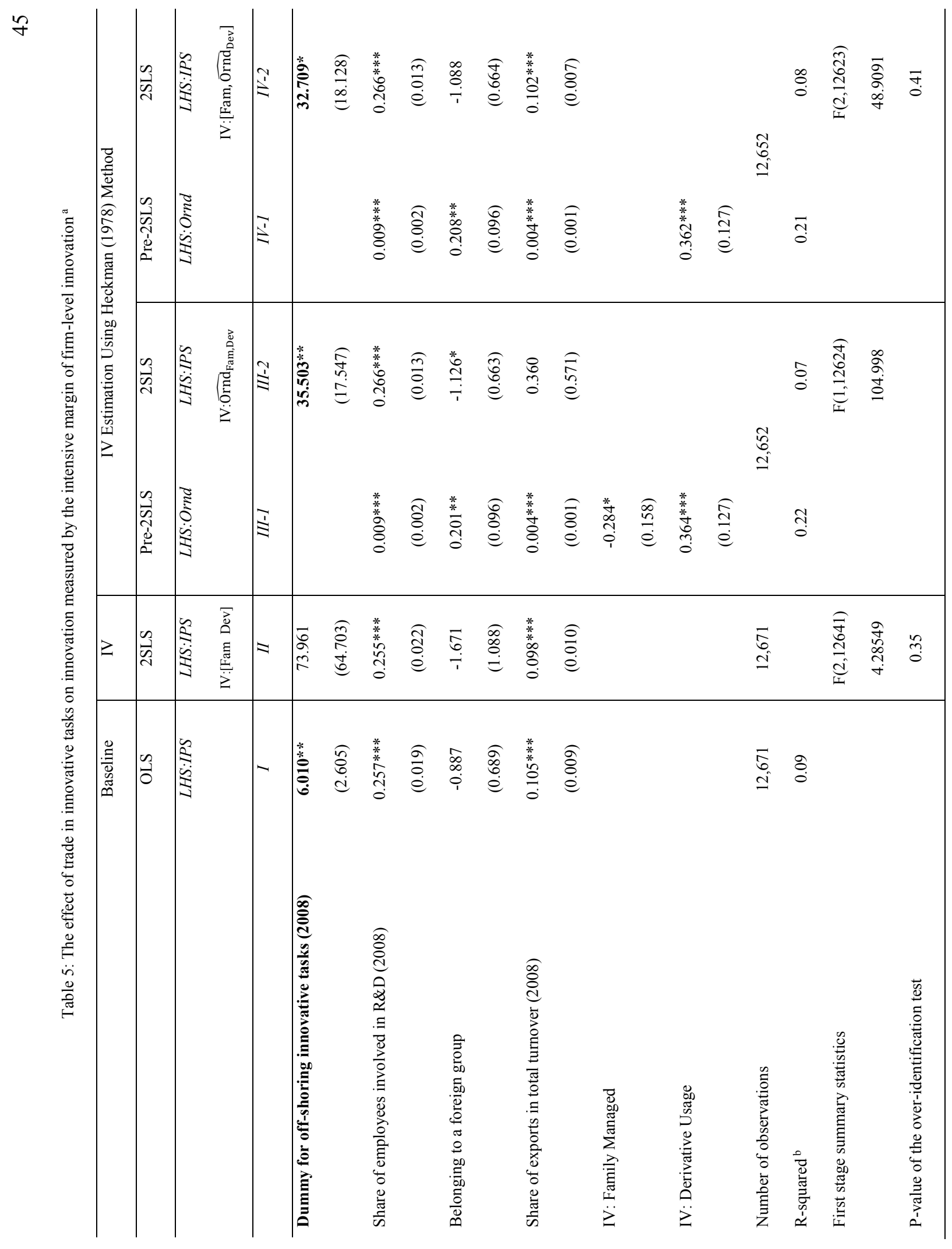




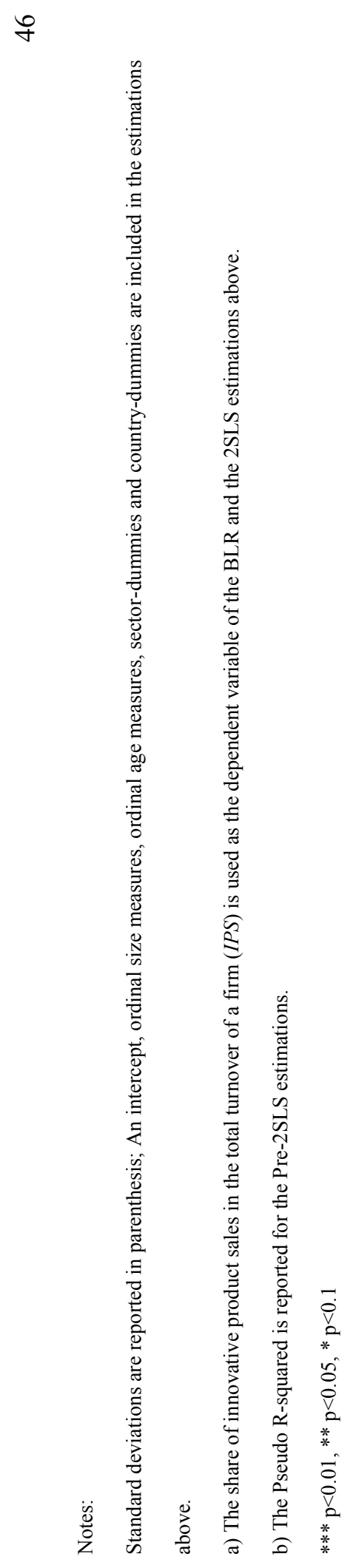




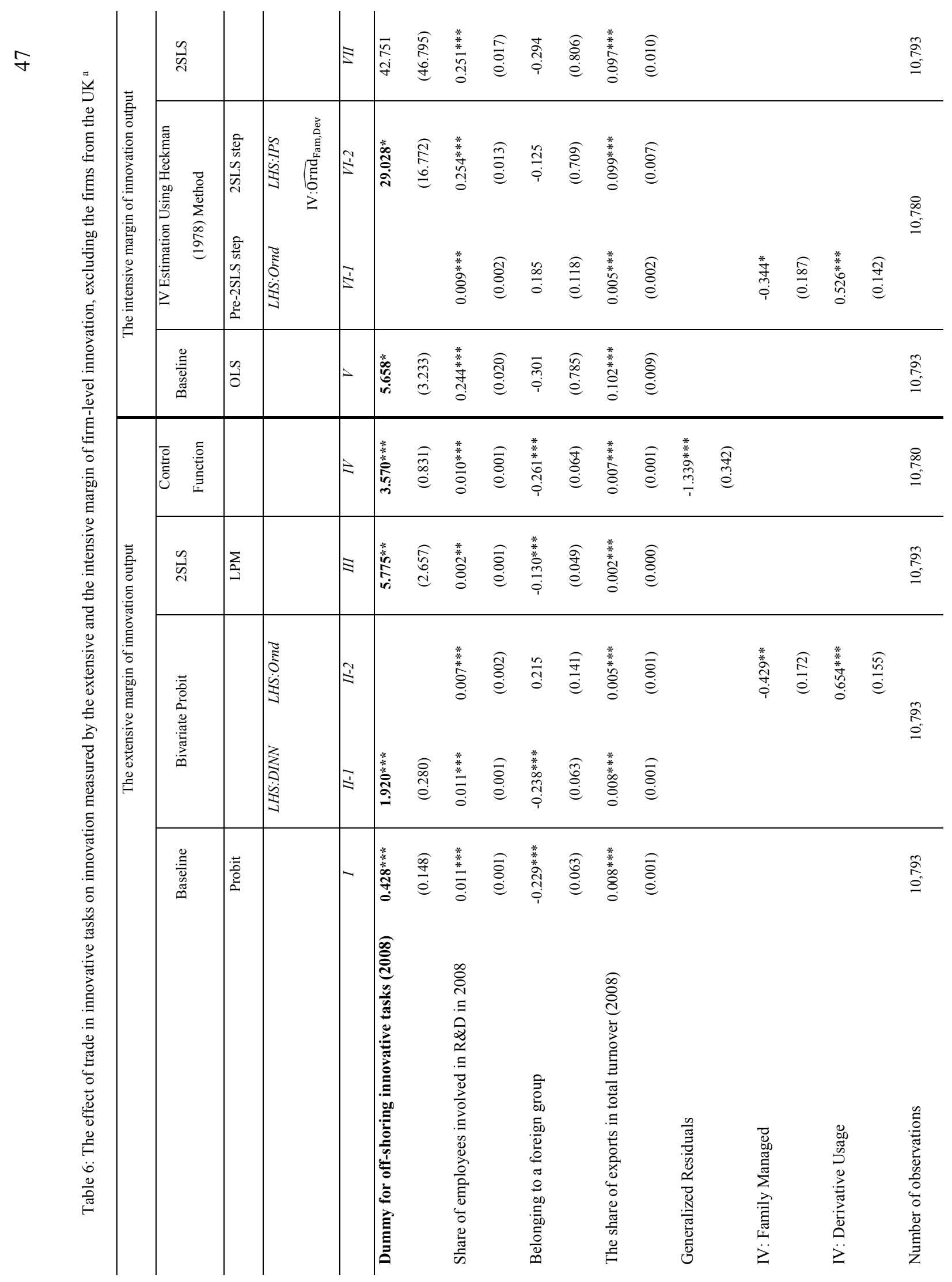




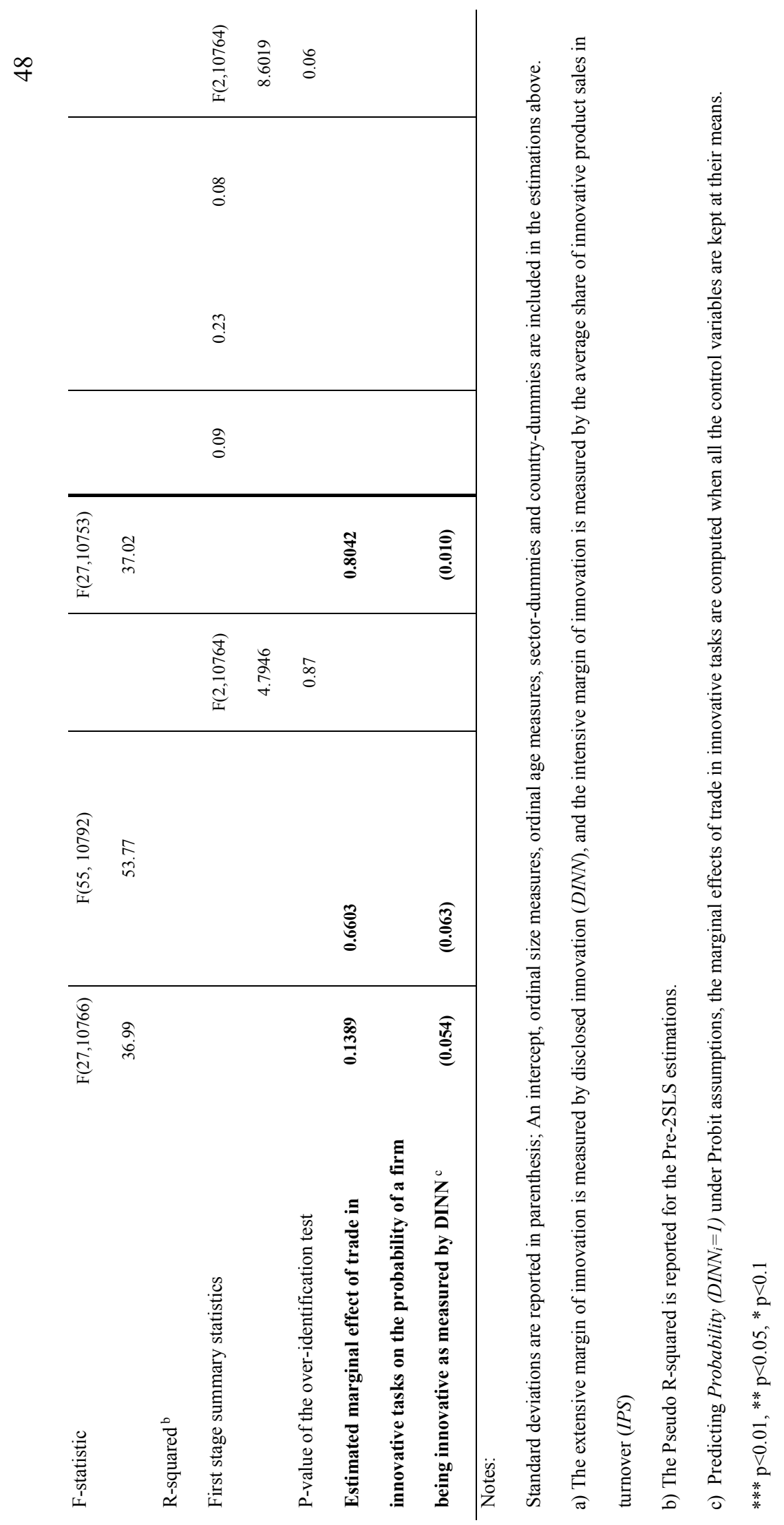




\section{Appendix 1}

\section{Tables}

Table A-1: Distribution of firms across countries and sectors

\begin{tabular}{c|ccccccccccccc}
\hline Country & \multicolumn{1}{c}{ Sector } & \multicolumn{1}{c}{ Total } \\
\hline \multicolumn{1}{l}{} & 1 & 2 & 3 & 4 & 5 & 6 & 7 & 8 & 9 & 10 & \multicolumn{2}{c}{11} \\
\hline AUT & 100 & 46 & 22 & 64 & 13 & 8 & 8 & 54 & 0 & 67 & 61 & 443 \\
FRA & 964 & 213 & 244 & 410 & 35 & 107 & 101 & 142 & 3 & 478 & 276 & 2,973 \\
GER & 568 & 350 & 192 & 371 & 199 & 95 & 61 & 103 & 4 & 489 & 503 & 2,935 \\
HUN & 108 & 63 & 40 & 68 & 22 & 20 & 14 & 17 & 0 & 68 & 68 & 488 \\
ITA & 687 & 238 & 169 & 481 & 227 & 108 & 80 & 88 & 8 & 554 & 381 & 3,021 \\
SPA & 648 & 463 & 148 & 223 & 280 & 121 & 106 & 212 & 0 & 326 & 305 & 2,832 \\
UK & 355 & 147 & 122 & 349 & 262 & 104 & 54 & 89 & 6 & 371 & 208 & 2,067 \\
\hline Total & 3,430 & 1,520 & 937 & 1,966 & 1,038 & 563 & 424 & 705 & 21 & 2,353 & 1,802 & 14,759
\end{tabular}

Table A-2: Distribution of firms across countries by economic activities

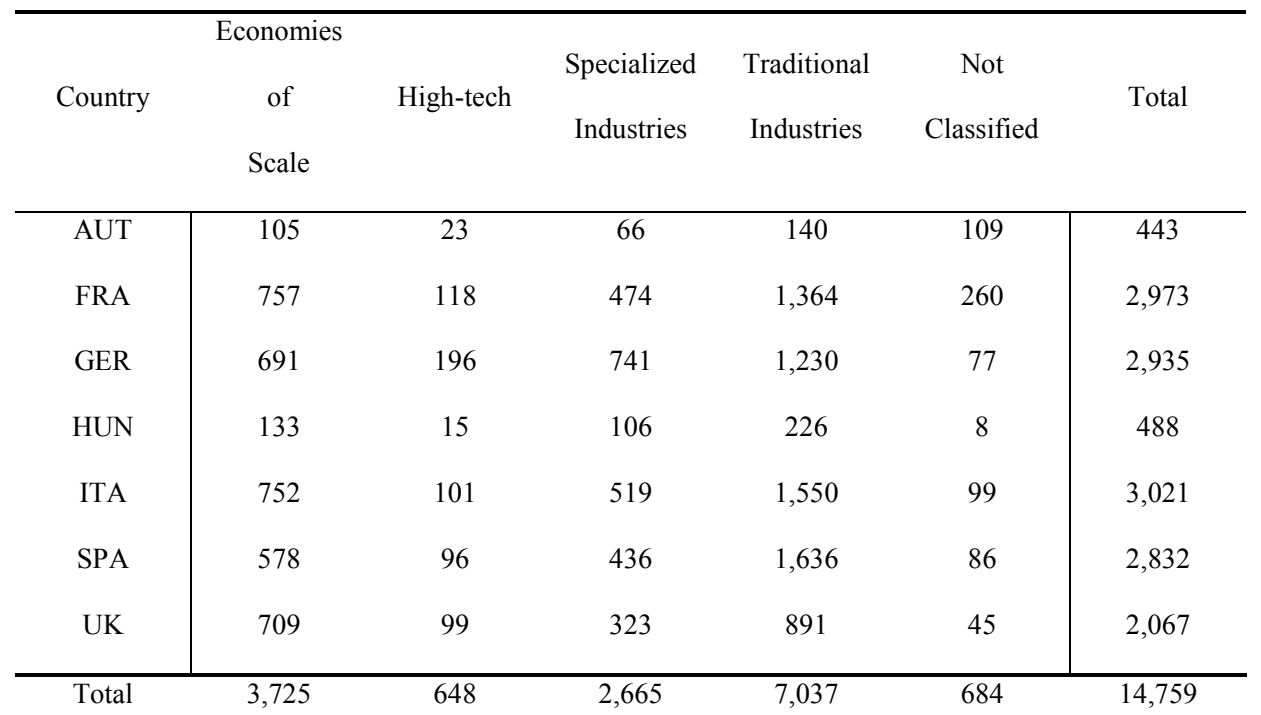


Table A-3: A list of the sectors in the sample ${ }^{\text {a }}$

- Manufacture of basic metals and fabricated metal products

- Manufacture of food product, beverage and tobacco

- Manufacture of rubber and plastic products

- Manufacture of textiles and textile products

Manufacture of pulp, paper and paper products

Publishing and printing

- Manufacture of leather and leather products

Manufacture of other non metallic mineral product

Manufacture of electrical and optical equipment

- Manufacture of chemicals, chemical products and man-made fibers

- Manufacture of transport equipment

- Manufacture of wood and wood products

- Manufacture of machine and equipment N.E.C

- $\quad$ Manufacturing N.E.C.

- $\quad$ Sector 9

Notes:

a) A randomized industry identifier is used in the EFIGE survey. 
Table A-4: The extensive margin of firm-level innovation measured by product/process innovation

\begin{tabular}{|c|c|c|c|c|c|c|c|c|c|}
\hline \multicolumn{5}{|c|}{$\begin{array}{c}\text { New-to-market product } \\
\text { innovator }\end{array}$} & \multicolumn{5}{|c|}{$\begin{array}{l}\text { Organizational } \\
\text { Innovator }^{\mathrm{b}}\end{array}$} \\
\hline & & No & Yes & Total & & & No & Yes & Total \\
\hline Product & No & 7,514 & 0 & 7,514 & Process & No & 7,346 & 920 & 8,266 \\
\hline Innovator $^{\text {a }}$ & Yes & 2,596 & 4,649 & 7,245 & Innovator $^{\mathrm{a}}$ & Yes & 2,722 & 3,771 & 6,493 \\
\hline Total & & 10,110 & 4,649 & 14,759 & Total & & 10,068 & 4,691 & 14,759 \\
\hline
\end{tabular}

\section{Notes:}

a) The product/process innovation carried out in years 2007-2009

b) Organizational innovation implied by product/process innovation.

Table A-5: Distribution of different types of firms across countries

\begin{tabular}{|c|c|c|c|c|c|c|}
\hline Country & Full Sample & Share ${ }^{a}$ & $\mathrm{MNCs}^{\mathrm{b}}$ & Share $^{\mathrm{a}}$ & $\begin{array}{l}\text { MNCs with off-shore } \\
\text { innovative efforts }\end{array}$ & Share ${ }^{a}$ \\
\hline AUT & 443 & $3 \%$ & 52 & $4 \%$ & 6 & $3 \%$ \\
\hline FRA & 2,973 & $20 \%$ & 285 & $23 \%$ & 39 & $23 \%$ \\
\hline GER & 2,935 & $19 \%$ & 307 & $25 \%$ & 43 & $25 \%$ \\
\hline HUN & 488 & $3 \%$ & 21 & $1 \%$ & 2 & $1 \%$ \\
\hline ITA & 3,021 & $20 \%$ & 221 & $18 \%$ & 16 & $9 \%$ \\
\hline SPA & 2,832 & $19 \%$ & 116 & $9 \%$ & 12 & $7 \%$ \\
\hline UK & 2,067 & $14 \%$ & 206 & $17 \%$ & 48 & $28 \%$ \\
\hline Total & 14,759 & & 1,208 & & 166 & \\
\hline
\end{tabular}

Notes:

a) Shares are computed for any given country relative to the total number of firms within sample and the sub-samples.

b) Firms who have reported some FDI or foreign contracts and arms length agreements are identified as MNCs.

c) Firms who have reported some FDI or foreign contracts and arms length agreements for R\&D, engineering and design services are identified as those who have off-shored their innovative tasks. 
Table A-6: A correlation matrix between the key variables and the instruments

\begin{tabular}{|c|c|c|c|c|c|c|c|c|}
\hline & \multicolumn{3}{|c|}{ Key response variables } & \multicolumn{2}{|c|}{$\begin{array}{c}\text { Selected control } \\
\text { variables }\end{array}$} & \multirow{2}{*}{$\begin{array}{c}\text { Treatment } \\
\text { of interest } \\
\text { Ornd }\end{array}$} & \multicolumn{2}{|c|}{ Instrumental Variables } \\
\hline & IPS & DINN & $\operatorname{PrdINN}^{\mathrm{a}}$ & $\begin{array}{c}\text { R\&D- } \\
\text { Emloyee } \\
\text { Share }\end{array}$ & $\begin{array}{l}\text { Export } \\
\text { Share }\end{array}$ & & Fam & Dev \\
\hline IPS & 1 & & & & & & & \\
\hline DINN & 0.2398 & 1 & & & & & & \\
\hline PrdINN ${ }^{a}$ & 0.5403 & 0.355 & 1 & & & & & \\
\hline R\&D-Emp. Share & 0.2188 & 0.1226 & 0.1845 & 1 & & & & \\
\hline Export Share & 0.198 & 0.2267 & 0.2271 & 0.0903 & 1 & & & \\
\hline Ornd & 0.0554 & 0.096 & 0.0625 & 0.043 & 0.0766 & 1 & & \\
\hline Fam & -0.0067 & -0.0892 & -0.0499 & 0.0437 & -0.1028 & -0.048 & 1 & \\
\hline Dev & 0.0352 & 0.1075 & 0.0766 & 0.0106 & 0.0912 & 0.047 & -0.046 & 1 \\
\hline
\end{tabular}

Notes:

a) PrdINN: Product innovation during 2007-9.

b) There are 1,964 firms for which I do not observe the share of export in total turnover. I also do not have enough information to compute the share of employees involved in R\&D for 17 firms. Thus, the number of observation in the correlation matrix above is less than the full sample size (14,759 observations).

\section{Survey questions}

In order to identify the MNCs in the sample, I make use of the following questions: ${ }^{1}$

\footnotetext{
${ }^{1}$ The questionnaire can be downloaded from http://www.bruegel.org/datasets/efigedataset/
} 
- Question D37: Does the firm currently run at least part of its production activity in another country?

- Yes, through direct investment (i.e. foreign affiliates/controlled firms)

- Yes, through contracts and arms length agreements with local firms ${ }^{2}$

$\circ$ No

- Question D38: Which percentage of 2008 turnover did the production activities through direct investment (foreign affiliates/controlled firms) represent?

- Question D49: Which percentage of 2008 turnover did the production activities through contracts and agreements represent?

I identify firm $i$ as an MNC if it runs at least part of its production activity in another country via FDI (when firm $i$ responds positively to the first choice in D37, and reports non-zero amount in D38) or contracts and arms length agreements (when firm i responds positively to the second choice in D37, and reports non-zero amount in D49).

In order to identify the MNCs who partake in trade in innovative tasks, I make use of the following questions (D46 for FDI activities, and D55 for contracts and arms length agreements):

- Question D46 and D55: Please indicate the main types of production activities carried out abroad amongst the following:

- Finished products

- Semi-finished products/components

- $R \& D$, engineering and design services

- Other business services

\footnotetext{
${ }^{2}$ Contracts and agreements refer to technical/manufacturing partnership agreements, such as job processing contracts and other subcontracts, and the sale of manufacturing licenses to independent foreign firms.
} 